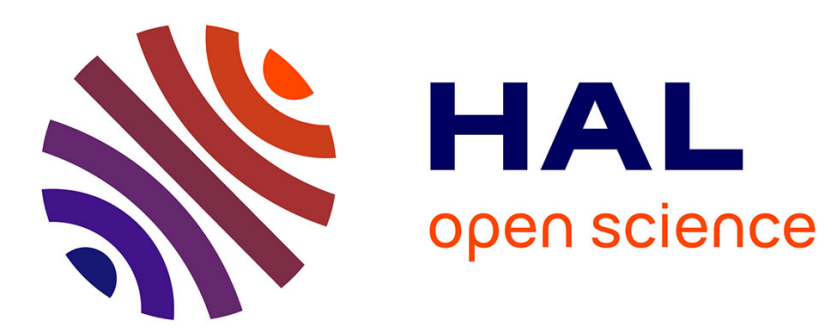

\title{
Induction Machine Speed Control with Flux Optimization
}

\author{
Hamid Ouadi, Fouad Giri, Abderrahim Elfadili, Luc Dugard
}

\section{To cite this version:}

Hamid Ouadi, Fouad Giri, Abderrahim Elfadili, Luc Dugard. Induction Machine Speed Control with Flux Optimization. Control Engineering Practice, 2010, 18 (1), pp.55-66. 10.1016/j.conengprac.2009.08.006 . hal-00412390

\section{HAL Id: hal-00412390 https://hal.science/hal-00412390}

Submitted on 9 Sep 2014

HAL is a multi-disciplinary open access archive for the deposit and dissemination of scientific research documents, whether they are published or not. The documents may come from teaching and research institutions in France or abroad, or from public or private research centers.
L'archive ouverte pluridisciplinaire HAL, est destinée au dépôt et à la diffusion de documents scientifiques de niveau recherche, publiés ou non, émanant des établissements d'enseignement et de recherche français ou étrangers, des laboratoires publics ou privés. 


\title{
Induction machine speed control with flux optimization
}

\author{
H. Ouadi ${ }^{\text {, F. Giri }}{ }^{\text {b,* }}$, A. Elfadili ${ }^{\text {a }}$, L. Dugard ${ }^{c}$ \\ a LAII, EMI, University of Rabat, Morocco \\ ${ }^{\mathrm{L}}$ GREYC Lab, University of Caen, Caen, France \\ ${ }^{\circ}$ GIPSA Lab, INPG, Grenoble, France
}

Keywords:

Induction machine

Magnetic saturation

Speed control

Flux optimization

Minimal current consumption

Backstepping control

\section{A B S T R A C T}

A new speed control strategy is developed, based on a machine model that accounts for the magnetic characteristic saturation. The control strategy includes a flux reference generator, designed to meet optimal operational conditions, and a speed controller designed using nonlinear techniques. Both flux generation and speed control laws involve the machine state variables. The performances of the proposed control strategy are formally analyzed and its supremacy with respect to standard control solutions is illustrated through simulation.

\section{Introduction}

It is widely recognized that the induction motor is going to become the main actuator for industrial purposes. Compared to other motors (e.g. DC machine), the induction motor provides a better power/mass ratio, simpler maintenance (no mechanical commutators) and relatively lower cost. However, the induction motor control problem is more complex, due to its multivariable and highly nonlinear nature. Finally, not all machine state variables are accessible to measurement.

Most previous control strategies for induction machine speed regulation are based on standard models obtained under the assumption that the machine magnetic characteristic is static and linear. As a matter of fact, such a characteristic is nonlinear and physical machines exhibit several nonlinear features e.g. flux saturation (Fig. 1). Nevertheless, standard models can still be used in speed control design, provided that the rotor flux regulation is performed around a fixed nominal value. This was generally the case, in previous control strategies, choosing a constant reference flux (Espinosa, Ortega, \& Nicklasson, 1997; Kim, Ortega, Charara, \& Vilain, 1997; Lubineau, Dion, Dugard, \& Roye, 2000; Ortega \& Espinosa, 1993; Ortega, Nicklasson, \& Espinosa-Perez, 1996; Von Raumer, Dion, Dugard, \& Thomas, 1994). In such a situation, the machine efficiency is maximal only when the load torque is close to its nominal value. However, in practical applications, the load torque is usually not a priori fixed and may be subject to wide

\footnotetext{
* Corresponding author.

E-mail addresses: fouad.giri@unicaen.fr, fouadgiri@yahoo.fr (F. Giri).
}

range variations (Leonard, 2001; Novotnak, Chiasson, \& Bodson, 1999). Then, keeping the flux near the nominal value will result in a useless energy stored in stator inductances, reducing the machine efficiency, especially when the load torque is small (compared to nominal load). Inversely, if the flux reference is given a small value, the achievable machine motor torque will not be sufficient to counteract large load torques. Therefore, speed control strategies involving constant flux reference are unable to guarantee optimal machine performances (optimality is generally understood in the sense of efficiency, power factor and maximal torque). To overcome the above shortcomings, it is necessary to develop new speed control strategies involving online tuning of the flux reference to track varying speed reference in presence of load torque changes. When these are important (ranging from 0 to nominal values), the optimal flux reference will in turn undergo wide range variations implying large excursions of the working point on the magnetic characteristic. Therefore, the development of speed control strategies, guaranteeing optimal machine performances, must rely on a machine model that takes into account the nonlinear feature of the magnetic characteristic. Fortunately, an example of such models was recently developed and experimentally validated (Ouadi, Giri, \& Dugard, 2004).

In the light of the above discussion, it becomes clear that speed control strategies for induction machines involve two main components: a speed/flux controller and an optimal flux reference generator. As already mentioned, the flux and speed references are generally chosen independently in earlier control strategies. Typically, the flux reference is generally given a (non-optimal) fixed value and the speed regulator is obtained (using various design techniques) from the machine standard model, supposing 


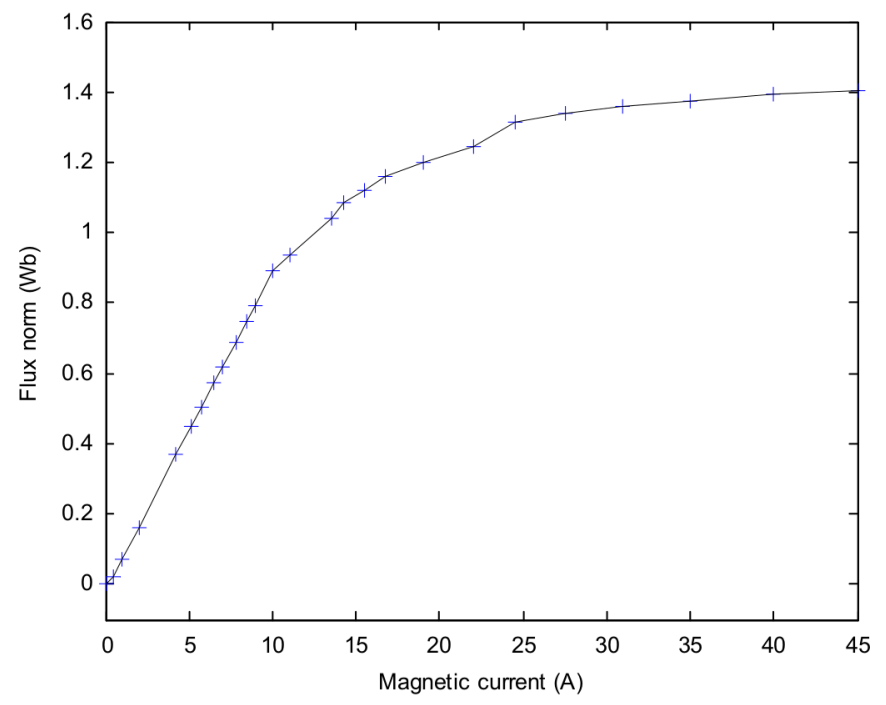

Fig. 1. Magnetic characteristic experimentally obtained in Ouadi et al. (2004) for a $7.5 \mathrm{KW}$ induction motor: rotor flux norm $\Phi_{r}(\mathrm{~Wb})$ versus magnetic current $I_{\mu}(\mathrm{A})$.

a linear magnetic characteristic (e.g. Espinosa et al., 1997; Kim et al., 1997; Leonard, 2001; Lubineau et al., 2000; Ortega \& Espinosa, 1993; Ortega et al., 1996; Von Raumer et al., 1994). A serious attempt to develop control strategies involving flux reference optimization was reported in (Novotnak et al., 1999): based on a field-oriented model accounting for magnetic saturation, a flux reference generator was designed to obtain online the maximum torque. As pointed out by the authors themselves, the saturation effect was accounted for in a 'somewhat ad hoc manner'. Specifically, a model of the saturated magnetic characteristic was just added to an existing (unsaturated) model of the induction machine (just as suggested in Heinemann \& Leonhard, 1990). This differs from the approach developed in (Ouadi et al., 2004) where the magnetic characteristic is accounted for, together with the basic electromagnetic laws, all along the modeling procedure. Furthermore, it is known that field-oriented models, like the one based upon in Novotnak et al. (1999), lead to controllers that are highly sensitive to rotor resistance variations. Finally, it is not formally proved in Novotnak et al. (1999) that the proposed control strategy actually achieves the desired control performances (closed-loop stability, speed and flux reference tracking). An alternative control strategy, refereed to maximum torque per Ampere, consists in obtaining stator current reference generators that maximize the machine torque, see e.g. Kwon \& Sudhoff (2005) and Wasynczuk et al. (1998). There, the current generators are designed, based on a standard field-oriented model neglecting the magnetic saturation. It is clear that neglecting the magnetic saturation effect contrasts with the objective of wide range torque variation control. Indeed, such an objective necessitates a wide range variation of the ( $d$-axis) stator current which entails large flux variations.

In the present paper, a new control strategy is developed that involves an optimal flux reference and a speed and flux controller. Both components are designed using the model developed in Ouadi et al. (2004) that accounts for magnetic saturation. The flux reference optimality is to be understood in the sense of stator current minimization. Therefore, the obtained optimal flux reference law involves the machine stator currents which are state variables. The speed/flux controller, designed by the backstepping technique, turns out to be quite different from previous standard control strategies that assume linear magnetic characteristic and involve constant flux references. The new controller
Table 1

List of acronyms.

\begin{tabular}{|c|c|}
\hline LM-model: & $\begin{array}{l}\text { Linear magnetic characteristic model (i.e. model neglecting } \\
\text { magnetic saturation) }\end{array}$ \\
\hline NLM-model: & $\begin{array}{l}\text { Nonlinear magnetic characteristic model (i.e. model accounting } \\
\text { for magnetic saturation) }\end{array}$ \\
\hline $\begin{array}{l}\text { LM-CF } \\
\text { strategy: }\end{array}$ & $\begin{array}{l}\text { Control strategy based on LM-model with constant flux } \\
\text { reference (i.e. standard strategy) }\end{array}$ \\
\hline $\begin{array}{l}\text { LM-OF } \\
\text { strategy: }\end{array}$ & $\begin{array}{l}\text { Control strategy based on LM-model, including optimal flux } \\
\text { generator }\end{array}$ \\
\hline $\begin{array}{l}\text { NLM-CF } \\
\text { strategy: }\end{array}$ & $\begin{array}{l}\text { Control strategy based on NLM-model, involving constant flux } \\
\text { reference }\end{array}$ \\
\hline NLM-OF: & $\begin{array}{l}\text { Strategy based on NLM-model with optimal flux generator (i.e. } \\
\text { new control strategy) }\end{array}$ \\
\hline SDOF: & $\begin{array}{l}\text { State dependent optimal flux reference (i.e. newly proposed } \\
\text { optimal flux generator) }\end{array}$ \\
\hline OCF: & Optimal current-flux characteristic \\
\hline
\end{tabular}

is formally proved to be globally asymptotically stable and enforces the speed to perfectly track its varying reference trajectory, despite the changing load torque. It is also checked through simulations that, in presence of load torque variations and rotor resistance uncertainties, the new control strategy is better than previous strategies, from the energetic viewpoint.

The paper is organized as follows: the induction machine model is presented in Section 2. In Section 3, the proposed control strategy is described and a flux reference optimization law is developed. The machine speed and flux controller is designed and formally analyzed in Section 4 . The controller performances are illustrated by simulation in Section 5 . A conclusion and reference list end the paper. For convenience, all acronyms used throughout are described in Table 1.

\section{Induction motor modeling}

In Ouadi et al. (2004), a model accounting for the saturation nature of the machine magnetic characteristic (Fig. 1) has been developed and experimentally validated using a $7.5 \mathrm{KW}$ induction motor. This model, named NLM throughout the paper, is defined by the following fifth order state-space representation:

$\dot{i}_{s \alpha}=-a_{2} i_{s \alpha}+\delta \phi_{r \alpha}+a_{3} p \Omega \phi_{r \beta}+a_{3} u_{s \alpha}$

$\dot{i}_{s \beta}=-a_{2} i_{s \beta}-a_{3} p \Omega \phi_{r \alpha}+\delta \phi_{r \beta}+a_{3} u_{s \beta}$

$\dot{\phi}_{r \alpha}=a_{1} i_{s \alpha}-L_{s e q} \delta \phi_{r \alpha}-p \Omega \phi_{r \beta}$

$\dot{\phi}_{r \beta}=a_{1} i_{s \beta}-L_{s e q} \delta \phi_{r \beta}+p \Omega \phi_{r \alpha}$

$\dot{\Omega}=\frac{p}{J}\left(\phi_{r \alpha} i_{s \beta}-\phi_{r \beta} i_{s \alpha}\right)-\frac{T_{L}}{J}-\frac{f}{J} \Omega$

where $i_{s \alpha}, i_{s \beta}$, are the $\alpha \beta$-components of the stator current, (state variables); $\phi_{r \alpha}, \phi_{r \beta}$ the rotor flux $\alpha \beta$-components, (state variables); $\Omega$ the motor speed, (state variable); $u_{s \alpha}, u_{s \beta}$ the $\alpha \beta$ components of the stator voltage, (control inputs); $R_{s}, R_{r}$ the stator and rotor resistances; $T_{L}$ the load torque; $f$ the friction coefficient; $p$ the number of pole pairs; and $L_{\text {seq }}$ the equivalent inductance (of both stator and rotor leakage) as seen from the stator.

In (1)-(3), the real constants $a_{i}$ 's are defined as follows:

$a_{1}=R_{r}, a_{2}=\frac{R_{s}+R_{r}}{L_{s e q}}, a_{3}=\frac{1}{L_{s e q}}$

Furthermore, $\delta$ is a function of the rotor flux norm (see Fig. 2). In Ouadi et al. (2004), this dependence was represented by a 
polynomial function approximation, namely

$\delta=W\left(\Phi_{r}\right)$

$W\left(\Phi_{r}\right)=b_{0}+b_{1} \Phi_{r}+\cdots+b_{m} \Phi_{r}^{m}$

The $b_{i}$ 's are constant coefficients, experimentally identified in Ouadi et al. (2004) using Fig. $1 . \Phi_{r}$ is the amplitude of the (instantaneous) rotor flux, denoted $\phi_{r}$. Then, one has:

$\Phi_{r}=\sqrt{\phi_{r \alpha}^{2}+\phi_{r \beta}^{2}}$

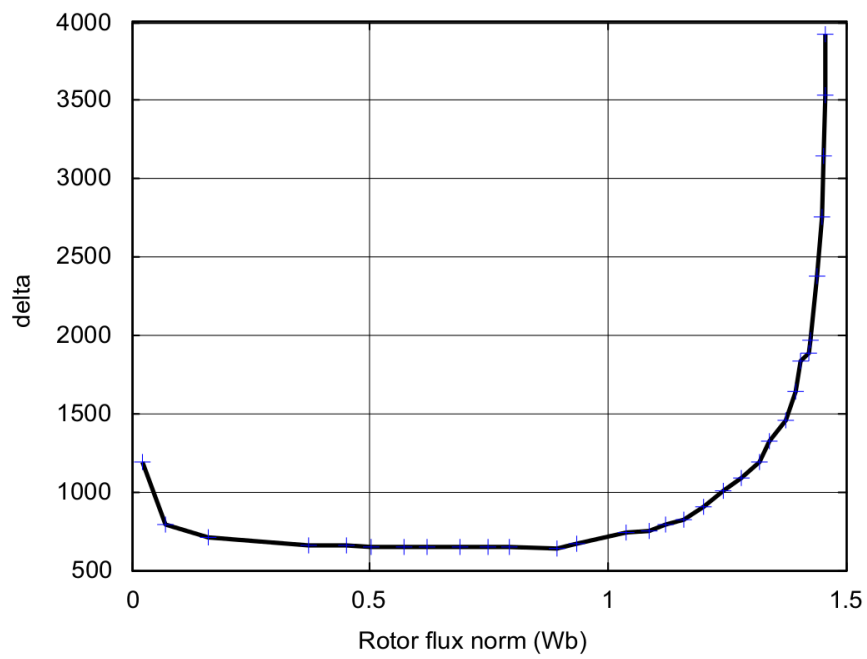

Fig. 2. Characteristic $\left(\delta, \Phi_{r}\right)$. The crosses indicate the points obtained directly from experimental data. The solid line represents the polynomial interpolation of experimental points. Units: $\delta\left(\Omega \mathrm{H}^{-2}\right), \Phi_{r}(\mathrm{~Wb})$.

Table 2

Different speed control strategies.

\begin{tabular}{llll}
\hline & & \multicolumn{2}{l}{ Flux reference generator } \\
\cline { 3 - 4 } & & Constant flux & SDOF \\
\hline Control design model & LM-model & LM-CF & LM-OF \\
& NLM-model & NLM-CF & NLM-OF \\
\hline
\end{tabular}

In the light of the above description, it becomes clear that the model (1)-(6) involves five state variables, $i_{s \alpha}, i_{s \beta}, \phi_{r \alpha}, \phi_{r \beta}$ and $\Omega$, and two control inputs, $u_{s \alpha}$ and $u_{s \beta}$. Two outputs will be controlled latter, $\Omega$ and $\Phi_{r}$. All the state variables are supposed to be measurable and all model parameters have known numerical values. The latter are described in Table 3 and correspond to an induction motor of $7.5 \mathrm{KW}$ power (Ouadi et al., 2004). In practice, the flux variables are generally not measurable. Then, a state observer must be developed to get estimates of unmeasured variables. Fortunately, such an observer is presently available (Giri, Elfadili, Ouadi, Dugard, \& Buche, 2008).

Finally, notice that the standard model, referred to LM-model, widely used in previous works is easily obtained from the above NLMmodel, letting $\delta$ be a constant parameter in (1)-(3), and denoted $\delta_{L}$, (Espinosa et al., 1997; Kim et al., 1997; Lubineau et al., 2000; Ortega and Espinosa, 1993; Ortega et al., 1996; Von Raumer et al., 1994). The fixed value of $\delta_{L}$ corresponds to the working point of interest on the machine magnetic characteristic. Every time the LM-model is considered in this paper, $\delta_{L}$ will correspond to the nominal flux value of the machine used in Ouadi et al. (2004). There, the nominal flux is $1.1 \mathrm{~Wb}$ and the resulting value of $\delta_{L}$ is given in Section 6 , together will all machine numerical characteristics (Table 3 ).

\section{Speed control strategies}

As mentioned previously, any control strategy for induction machines is characterized by two main components: a flux reference generator and a speed (and possibly flux) controller. Depending on the way these components are designed, four control strategies are considered, (see Table 2 and Figs. 3 and 4). In the existing literature (Espinosa et al., 1997; Kim et al., 1997; Lubineau et al., 2000; Ortega and Espinosa, 1993; Ortega et al., 1996; Von Raumer et al., 1994), the most popular of them is the standard control strategy, here called LM-CF which is characterized by a non-optimal constant flux reference and a speed/flux controller designed from the LM-model. There, the constant flux reference should normally be given the machine flux nominal value (located at the elbow region on the magnetic characteristic). As emphasized in the Introduction, the resulting control performances are not satisfactory from an energetic viewpoint, especially in presence of small loads.

Recently, some works suggested LM-OF strategies (Table 2) including state-dependent optimal flux generators (Kwon and

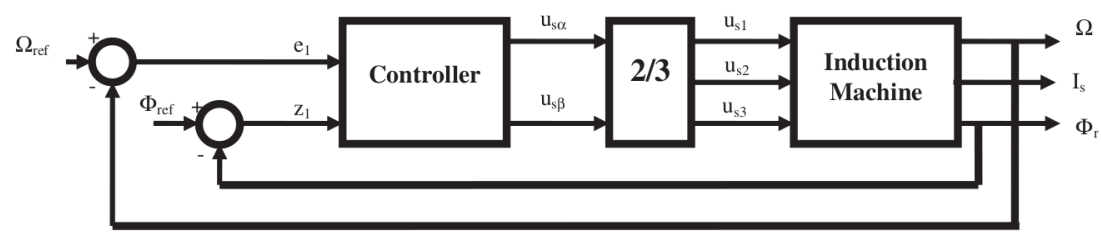

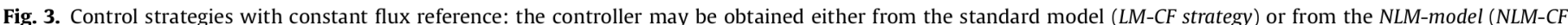
strategy).

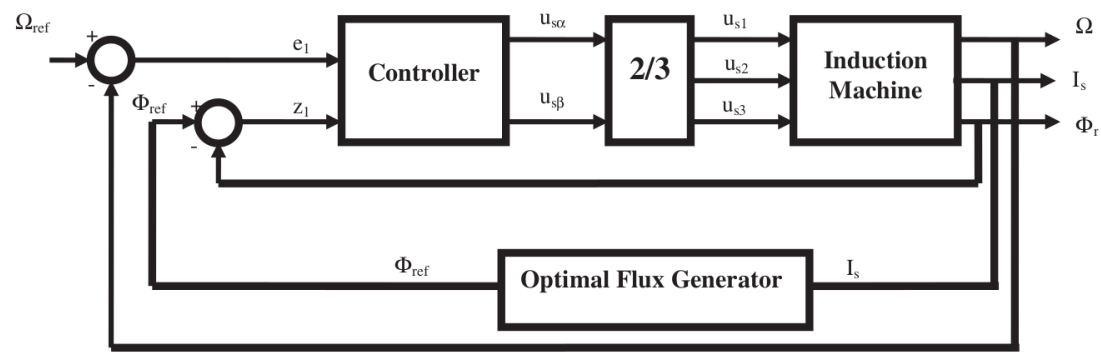

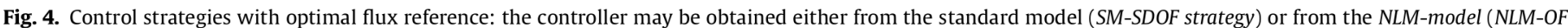
strategy). 
Sudhoff, 2005; Novotnak et al., 1999; Wasynczuk et al., 1998). However, the involved speed regulators are still obtained from the standard model, which limits their capability to track the varying optimal flux reference, leading to non-optimal machine performances. Such shortcomings will be illustrated in Section 6 .

The NLM-CF control strategy (Table 2) is characterized by a constant flux setpoint and a speed regulator issued from the NLMmodel (Fig. 3). Such a strategy is practically useless as no benefit is gained from model complexity if the flux reference is kept constant.

The present paper focuses on the new control strategy (NLM$O F$ ) that consists in designing an optimal flux reference generator and a speed/flux controller (Fig. 4). The latter is designed using a nonlinear control technique based on the NLM-model (1)-(6) that takes into account the saturation feature of the machine magnetic characteristic. The flux reference optimality, together with the controller tracking ability (to match varying speed and flux references), is expected to guarantee satisfactory machine performances (efficiency, power factor, maximal torque,...). Presently, the minimization of the stator current needed for producing a given load torque is looked for. This will be performed by acting on the rotor flux norm according to the control principle scheme of Fig. 4. The proposed control strategy is presented in detail in Sections 4 and 5.

\section{Optimal flux reference generator}

In the $d-q$ oriented reference frame, the flux $q$-component is null and all state variables are constant in steady-state. Then, the machine electromagnetic torque $T_{e}$ is expressed as follows:

$T_{e}=p \phi_{r d} i_{s q}=p \Phi_{r} i_{s q}$

On the other hand, it follows from (1) that the steady-state current $i_{s d}$ can be given the following expression:

$i_{s d}=\frac{L_{s e q}}{a_{1}} \delta \Phi_{r}$

In (7a-b), $i_{s d}$ and $i_{s q}$ denote the $d$ - and $q$-components of the stator current. Also, recall the stator current norm expression:

$I_{s}^{2}=i_{s q}^{2}+i_{s q}^{2}$

Then, using (7) and (8), one gets the following expression of the electromagnetic torque:

$T_{e}=p \Phi_{r} \sqrt{I_{s}^{2}-\left(\frac{L_{s e q}}{a_{1}} \delta \Phi_{r}\right)^{2}}$

Solving (9) with respect to $I_{s}$ leads to

$I_{s}=H_{T_{e}}\left(\Phi_{r}\right) \stackrel{\text { def }}{=} \sqrt{\left(\frac{T_{e}}{p \Phi_{r}}\right)^{2}+\left(\frac{L_{s e q}}{a_{1}} \delta \Phi_{r}\right)^{2}}$

Fig. 5 shows the family of curves $I_{s}=H_{T_{e}}\left(\Phi_{r}\right)$ that represents (for the induction machine characterized by the numerical parameters of Table 3 ) the stator current $I_{s}$ versus the flux $\Phi_{r}$, for various values of the electromagnetic torque $T_{e}$. For a given $T_{e}$, the best choice of the flux reference is the abscissa of the lowest point on the corresponding curve $I_{S}=H_{T_{e}}\left(\Phi_{r}\right)$. Indeed, the absorbed stator current is minimal at this point. That is, the best flux reference value, for a given electromagnetic torque $T_{e}$, corresponds to the abscissa of the minimum point on the curve $I_{s}=H_{T_{e}}\left(\Phi_{r}\right)$. Fortunately, such a curve has (see Fig. 5) a unique global minimum, simply denoted $\left(I_{T_{e}}^{*}, \Phi_{T_{e}}^{*}\right)$. The coordinates of such a minimum can theoretically be obtained by solving the following >equation with respect to $\Phi_{r}$ :

$\frac{d H_{T_{e}}\left(\Phi_{r}\right)}{d \Phi_{r}}=\frac{d}{d \Phi_{r}} \sqrt{\left(\frac{T_{e}}{p \Phi_{r}}\right)^{2}+\left(\frac{L_{s e q}}{a_{1}} \delta \Phi_{r}\right)^{2}}=0$

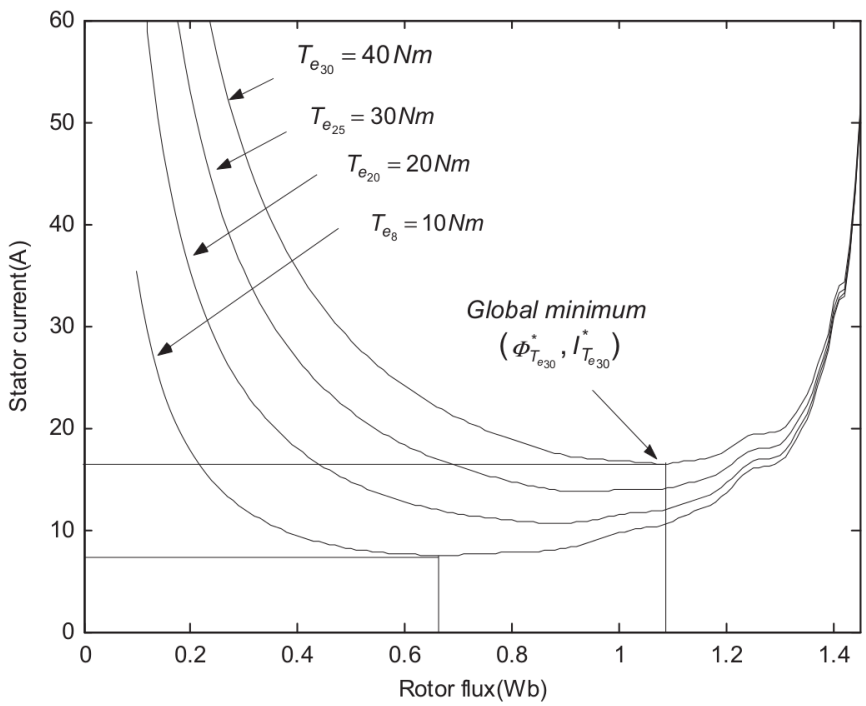

Fig. 5. The curves $I_{S}=H_{T_{e_{f}}}\left(\Phi_{r}\right)$ for $j=8,20,25$ and 30. It is seen that each curve has a global minimum (explicitly indicated for $T_{e_{8}}$ and $T_{e_{30}}$ ). The coordinates of the minimum associated to $T_{e_{j}}$ are denoted $\left(\Phi_{T_{e_{j}}}^{*}, I_{T_{e_{j}}}^{*}\right)$. For instance $\left(\Phi_{T_{e 30}}^{*}, I_{T_{e 30}}^{*}=\right.$ $(1.1 \mathrm{~Wb}, 16.22 \mathrm{~A})$ and $\left(\Phi_{T_{e B}}^{*}, I_{T_{e 8}}^{*}\right)=(0.66 \mathrm{~Wb}, 7.45 \mathrm{~A})$.

Table 3

Numerical values of considered motor characteristics.

\begin{tabular}{llcl}
\hline Characteristic & Symbol & Value & Unit \\
\hline Nominal power & $P_{N}$ & 7.5 & $\mathrm{KW}$ \\
Nominal voltage & $U_{s n}$ & 380 & $\mathrm{~V}$ \\
Nominal flux & $\Phi_{r n}$ & 1.1 & $\mathrm{~Wb}$ \\
Stator resistance & $R_{S}$ & 0.63 & $\Omega$ \\
Rotor resistance & $R_{r}$ & 0.4 & $\Omega$ \\
Inertia moment & $J$ & 0.22 & $\mathrm{Kg} \mathrm{m}^{2}$ \\
Friction coefficient & $f$ & 0.001 & $\mathrm{~N} \mathrm{~m} \mathrm{~s} \mathrm{rd}^{-1}$ \\
Number of pole pairs & $p$ & 2 & \\
Leakage equivalent inductance & $L_{\text {seq }}$ & 7 & $\mathrm{mH}$ \\
\hline
\end{tabular}

However, the analytical solution of this equation is difficult to find because the quantity $\delta$ is itself a polynomial function of $\Phi_{r}$ as shown by (4)-(5). ${ }^{1}$ Therefore, a graphical search of global minima is privileged in the present study.

Based on the above remarks, a sample of 30 relevant torque values $T_{e_{j}}(j=1, \ldots, 30)$ has been a priori selected and the corresponding global minima $\left(\Phi_{T_{e_{j}}}^{*}, I_{T_{e_{j}}}^{*}\right)$ can be graphically determined as illustrated by Fig. 5 where all the curves correspond to the induction machine characterized by the numerical parameters of Table 3. Doing so, a set of 30 global minima $\left(\Phi_{T_{e_{j}}}^{*}, I_{T_{e_{j}}}^{*}\right)$ $(j=1, \ldots, 30)$ has been obtained. Then a $n$ th-order polynomial function $F($.$) , fitting in the least squares sense the set of minima$ points, has been built. The degree $n=14$ turned out to be convenient for the considered data. The polynomial thus constructed is denoted:

$F\left(I_{s}\right)=h_{n} I_{s}^{n}+h_{n-1} I_{s}^{n-1}+\cdots+h_{1} I_{s}+h_{0}$

where the coefficients $h_{j}$ have the numerical values of Table 4 (for the machine characterized by the parameters of Table 3 ). $F($.$) is$ graphically plotted in Fig. 6 which will be referred to optimal current-flux (OCF) characteristic. Recall that optimality is

\footnotetext{
${ }^{1}$ It is worthy recalling that the polynomial dependence of $\delta$ on $\Phi_{r}$ is a consequence of the saturation feature of the machine magnetic characteristic. Indeed, if such a feature is neglected $\delta$ becomes a constant parameter.
} 


\begin{tabular}{|c|c|c|c|c|}
\hline$h_{14}=-1.36 \times 10^{-32}$ & $h_{13}=4.72 \times 10^{-29}$ & $h_{12}=-7.35 \times 10^{-26}$ & $h_{11}=6.8 \times 10^{-23}$ & $h_{10}=-4.17 \times 10^{-20}$ \\
\hline$h_{9}=1.78 \times 10^{-17}$ & $h_{8}=-5.42 \times 10^{-15}$ & $h_{7}=1.19 \times 10^{-12}$ & $h_{6}=-1.89 \times 10^{-10}$ & $h_{5}=2.16 \times 10^{-8}$ \\
\hline$h_{4}=-1.74 \times 10^{-6}$ & $h_{3}=9.97 \times 10^{-5}$ & $h_{2}=-0.0040$ & $h_{1}=0.1041$ & $h_{0}=-0.0895$ \\
\hline
\end{tabular}

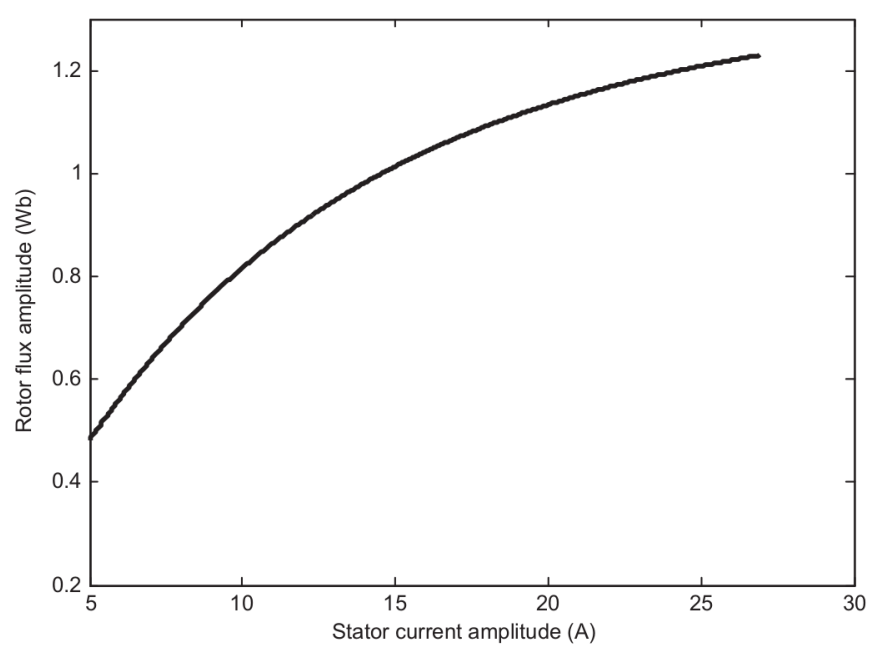

Fig. 6. OCF characteristic obtained interpolating the points $\left(\Phi_{T_{e_{j}}}^{*}, I_{T_{e_{j}}}^{*}\right)$ corresponding to the machine characterized by Table 3 .

understood in the sense of minimal absorbed stator current $I_{S}$ for a given torque $T_{e}$.

\section{Speed and flux controller design and analysis}

The problem of interest is the control of the rotor speed and flux norm for the saturated induction machine described by (1)-(6). The speed reference $\Omega_{\text {ref }}$ is any bounded and derivable function of time with its two first derivatives available and bounded. These properties can always be achieved by filtering the reference through secondorder linear filters. The flux reference $\Phi_{\text {ref }}$ is tuned online so that, if $\Phi_{r}=\Phi_{\text {ref }}$ (with $\Phi_{r}=\sqrt{\phi_{r \alpha}^{2}+\phi_{r \beta}^{2}}$ ) the machine will operate in optimal conditions (in the sense of absorbed stator current). In the light of Section 3.2, it follows that such an optimality will be guaranteed if the flux reference is computed online by the relation $\Phi_{\text {ref }}=F\left(I_{s}\right)$ plotted in Fig. 6 . The controller design is performed in two steps using the backstepping technique (Krstic, Kanellakopoulos, \& Kokotovic, 1995) First, introduce the tracking errors:

$e_{1}=\Omega_{\text {ref }}-\Omega$

$z_{1}=\Phi_{r e f}^{2}-\left(\phi_{r \alpha}^{2}+\phi_{r \beta}^{2}\right)$

Step 1. It follows from (1)-(3) that the errors $e_{1}$ and $z_{1}$ undergo the differential equations:

$$
\begin{aligned}
\dot{e}_{1}= & \dot{\Omega}_{r e f}-\frac{p}{J}\left(\phi_{r \alpha} i_{s \beta}-\phi_{r \beta} i_{s \alpha}\right)+\frac{T_{L}}{J}+\frac{f}{J} \Omega \\
\dot{z}_{1}= & 2 \Phi_{r e f} \dot{\Phi}_{r e f}-2 \phi_{r \alpha} \dot{\phi}_{r \alpha}-2 \phi_{r \beta} \dot{\phi}_{r \beta} \\
= & 2 \Phi_{r e f} \dot{\Phi}_{r e f}-2 \phi_{r \alpha}\left(-L_{s e q} \delta \phi_{r \alpha}+a_{1} i_{s \alpha}-\omega \phi_{r \beta}\right) \\
& -2 \phi_{r \beta}\left(-L_{s e q} \delta \phi_{r \beta}+a_{1} i_{s \beta}+\omega \phi_{r \alpha}\right) \\
= & 2 \Phi_{r e f} \dot{\Phi}_{r e f}-2 a_{1}\left(\phi_{r \alpha} i_{s \alpha}+\phi_{r \beta} i_{s \beta}\right)+2 L_{s e q} \delta\left(\phi_{r \alpha}^{2}+\phi_{r \beta}^{2}\right) \\
= & 2 \Phi_{r e f} \dot{\Phi}_{r e f}-2 a_{1}\left(\phi_{r \alpha} i_{s \alpha}+\phi_{r \beta} i_{s \beta}\right)+2 L_{s e q} \delta\left(\Phi_{r e f}^{2}-z_{1}\right)
\end{aligned}
$$

In (13) and (14), the quantities $(p / J)\left(\phi_{r \alpha} i_{s \beta}-\phi_{r \beta} i_{s \alpha}\right)$ and $2 a_{1}\left(\phi_{r \alpha} i_{s \alpha}+\phi_{r \beta} i_{s \beta}\right)$ stand for virtual control signals. If they were the actual control signals, the error system (13)-(14) could be globally asymptotically stabilized by letting $(p / J)\left(\phi_{r \alpha} i_{s \beta}-\right.$ $\left.\phi_{r \beta} i_{s \alpha}\right)=\mu_{1}$ and $2 a_{1}\left(\phi_{r \alpha} i_{s \alpha}+\phi_{r \beta} i_{s \beta}\right)=v_{1}$ with

$\mu_{1} \stackrel{\text { def }}{=} c_{1} e_{1}+\dot{\Omega}_{\text {ref }}+\frac{T_{L}}{J}+\frac{f}{J} \Omega$

$v_{1} \stackrel{\text { def }}{=} d_{1} z_{1}+2 \Phi_{\text {ref }} \dot{\Phi}_{r e f}+2 L_{s e q} \delta\left(\Phi_{r e f}^{2}-z_{1}\right)$

where $c_{1}$ and $d_{1}$ are any positive design parameters. Indeed, considering the Lyapunov function:

$V_{1}=\frac{1}{2}\left(e_{1}^{2}+z_{1}^{2}\right)$

One would get from (13)-(16), letting $(p / J)\left(\phi_{r \alpha} i_{s \beta}-\phi_{r \beta} i_{s \alpha}\right)=\mu_{1}$ and $2 a_{1}\left(\phi_{r \alpha} i_{s \alpha}+\phi_{r \beta} i_{s \beta}\right)=v_{1}$ :

$\dot{V}_{1}=-c_{1} e_{1}^{2}-d_{1} z_{1}^{2}$

This would prove the global asymptotic stability of the system (13)-(16). As the quantities $(p / J)\left(\phi_{r \alpha} i_{s \beta}-\phi_{r \beta} i_{s \alpha}\right)$ and $2 a_{1}\left(\phi_{r \alpha} i_{s \alpha}+\right.$ $\left.\phi_{r \beta} i_{s \beta}\right)$ are not the actual control signals, they cannot be let equal to $\mu_{1}$ and $\nu_{1}$, respectively. Nevertheless, the expressions of $\mu_{1}$ and $v_{1}$ are retained as first stabilizing functions and the new errors are introduced:

$e_{2}=\mu_{1}-\frac{p}{J}\left(\phi_{r \alpha} i_{s \beta}-\phi_{r \beta} i_{s \alpha}\right)$

$z_{2}=v_{1}-2 a_{1}\left(\phi_{r \alpha} i_{s \alpha}+\phi_{r \beta} i_{s \beta}\right)$

Then, using the notations (15)-(20), the dynamics of the errors $e_{1}$ and $z_{1}$, initially described by (13)-(16), can be rewritten as follows:

$\dot{e}_{1}=-c_{1} e_{1}+e_{2}$

$\dot{z}_{1}=-d_{1} z_{1}+z_{2}$

Similarly, the time-derivative of $V_{1}$ can be expressed as a function of the new errors as follows:

$\dot{V}_{1}=-c_{1} e_{1}^{2}-d_{1} z_{1}^{2}+e_{1} e_{2}+z_{1} z_{2}$

Step 2. The second design step consists in choosing the actual control signals, $u_{s \alpha}$ and $u_{s \beta}$, so that all errors $\left(e_{1}, z_{1}, e_{2}, z_{2}\right)$ converge to zero. To this end, one has to manage in such a way that these errors depend on the actual control signals $\left(u_{s \alpha}, u_{s \beta}\right)$. Let us first focus on $e_{2}$; it follows from (19) that:

$\dot{e}_{2}=\dot{\mu}_{1}-\frac{p}{J}\left(\dot{\phi}_{r \alpha} i_{s \beta}+\phi_{r \alpha} \dot{i}_{s \beta}-\dot{\phi}_{r \beta} i_{s \alpha}-\phi_{r \beta} \dot{i}_{s \alpha}\right)$

Using (1a-b)-(3) and (15), one gets from (23):

$$
\begin{aligned}
\dot{e}_{2}= & \left(c_{1} \dot{e}_{1}+\ddot{\Omega}_{r e f}+\frac{\dot{T}_{L}}{J}+\frac{f}{J} \dot{\Omega}\right)-\frac{p}{J}\left(\dot{\phi}_{r \alpha} i_{s \beta}-\dot{\phi}_{r \beta} i_{s \alpha}\right)-\frac{p}{J}\left(\phi_{r \alpha} i_{s \beta}-\phi_{r \beta} i_{s \alpha}\right) \\
= & c_{1}\left(-c_{1} e_{1}+e_{2}\right)+\ddot{\Omega}_{r e f}+\frac{\dot{T}_{L}}{J}+\frac{f}{J}\left(\frac{p}{J}\left(\phi_{r \alpha} i_{s \beta}-\phi_{r \beta} i_{s \alpha}\right)\right. \\
& \left.-\frac{T_{L}}{J}-\frac{f}{J} \Omega\right)-\frac{p}{J}\left(\left(-L_{s e q} \delta \phi_{r \alpha}+a_{1} i_{s \alpha}-\omega \phi_{r \beta}\right) i_{s \beta}\right. \\
& \left.-\left(-L_{s e q} \delta \phi_{r \beta}+a_{1} i_{s \beta}+\omega \phi_{r \alpha}\right) i_{s \alpha}\right)
\end{aligned}
$$




$$
\begin{aligned}
& -\frac{p}{J} \phi_{r \alpha}\left(\delta \phi_{r \beta}-a_{3} \omega \phi_{r \alpha}-a_{2} i_{s \beta}+a_{3} u_{s \beta}\right) \\
& +\frac{p}{J} \phi_{r \beta}\left(\delta \phi_{r \alpha}+a_{3} \omega \phi_{r \beta}-a_{2} i_{s \alpha}+a_{3} u_{s \alpha}\right)
\end{aligned}
$$

For convenience, this equation is given the following compact form:

$\dot{e}_{2}=\mu_{2}+\frac{p}{J} a_{3}\left(\phi_{r \beta} u_{s \alpha}-\phi_{r \alpha} u_{s \beta}\right)$

with

$$
\begin{aligned}
\mu_{2}= & c_{1}\left(-c_{1} e_{1}+e_{2}\right)+\ddot{\Omega}_{r e f}+\frac{\dot{T}_{L}}{J}+\frac{f}{J}\left(\frac{p}{J}\left(\phi_{r \alpha} i_{s \beta}-\phi_{r \beta} i_{s \alpha}\right)-\frac{T_{L}}{J}-\frac{f}{J} \Omega\right) \\
& -\frac{p}{J}\left(-L_{s e q} \delta \phi_{r \alpha}+a_{1} i_{s \alpha}-\omega \phi_{r \beta}\right) i_{s \beta}+\frac{p}{J}\left(-L_{s e q} \delta \phi_{r \beta}+a_{1} i_{s \beta}+\omega \phi_{r \alpha}\right) i_{s \alpha} \\
& -\frac{p}{J} \phi_{r \alpha}\left(\delta \phi_{r \beta}-a_{3} \omega \phi_{r \alpha}-a_{2} i_{s \beta}\right)+\frac{p}{J} \phi_{r \beta}\left(\delta \phi_{r \alpha}+a_{3} \omega \phi_{r \beta}-a_{2} i_{s \alpha}\right)
\end{aligned}
$$

Similarly, it follows from (20) and (1a-b)-(3) that $z_{2}$ undergoes the following differential equation:

$\dot{z}_{2}=\dot{v}_{1}-2 a_{1}\left(\dot{\phi}_{r \alpha} i_{s \alpha}+\phi_{r \alpha} \dot{i}_{s \alpha}+\dot{\phi}_{r \beta} i_{s \beta}+\phi_{r \beta} \dot{i}_{s \beta}\right)$

Using (1a-b)-(3) and (16), it follows from (27):

$$
\begin{aligned}
\dot{z}_{2}= & d_{1} \dot{z}_{1}+2 \Phi_{r e f} \ddot{\Phi}_{r e f}+2 \dot{\Phi}_{r e f}^{2}+2 L_{s e q} \delta\left(2 \Phi_{r e f} \dot{\Phi}_{r e f}\right. \\
& \left.-\dot{z}_{1}\right)+2 L_{s e q} \dot{\delta}\left(\Phi_{r e f}^{2}-z_{1}\right)-2 a_{1}\left(\left(-L_{s e q} \delta \phi_{r \alpha}+a_{1} i_{s \alpha}-\omega \phi_{r \beta}\right) i_{s \alpha}\right. \\
& +\phi_{r \alpha}\left(\delta \phi_{r \alpha}+a_{3} \omega \phi_{r \beta}-a_{2} i_{s \alpha}+a_{3} u_{s \alpha}\right) \\
& +\left(-L_{s e q} \delta \phi_{r \beta}+a_{1} i_{s \beta}+\omega \phi_{r \alpha}\right) i_{s \beta} \\
& \left.+\phi_{r \beta}\left(\delta \phi_{r \beta}-a_{3} \omega \phi_{r \alpha}-a_{2} i_{s \beta}+a_{3} u_{s \beta}\right)\right)
\end{aligned}
$$

where the derivative of $\delta$ is obtained from (4):

$\dot{\delta}=\frac{d \delta}{d \Phi_{r}} \frac{d \Phi_{r}}{d t}=\frac{d \delta}{d \Phi_{r}}\left(\frac{\phi_{r \alpha}}{\Phi_{r}} \dot{\phi}_{r \alpha}+\frac{\phi_{r \beta}}{\Phi_{r}} \dot{\phi}_{r \beta}\right)$

Note that the derivative $d \delta / d \Phi_{r}$ is easily computed due to the polynomial nature of (5). Also, the derivatives $\dot{\phi}_{r \alpha}, \dot{\phi}_{r \beta}$ are readily obtained using model equations (2a-b).

Eq. (28) can be given the following compact form:

$\dot{z}_{2}=v_{2}-2 a_{1} a_{3}\left(\phi_{r \beta} u_{s \beta}+\phi_{r \alpha} u_{s \alpha}\right)$

with

$$
\begin{aligned}
v_{2}= & d_{1}\left(-d_{1} z_{1}+z_{2}\right)+2 \Phi_{r e f} \ddot{\Phi}_{r e f}+2 \dot{\Phi}_{r e f}^{2}+2 L_{s e q} \delta\left(2 \Phi_{r e f} \dot{\Phi}_{r e f}-\dot{z}_{1}\right) \\
& +2 L_{s e q} \dot{\delta}\left(\Phi_{r e f}^{2}-z_{1}\right)-2 a_{1}\left(\left(-L_{s e q} \delta \phi_{r \alpha}+a_{1} i_{s \alpha}-\omega \phi_{r \beta}\right) i_{s \alpha}\right. \\
& \left.+\left(-L_{s e q} \delta \phi_{r \beta}+a_{1} i_{s \beta}+\omega \phi_{r \alpha}\right) i_{s \beta}\right)+\phi_{r \beta}\left(\delta \phi_{r \beta}-a_{2} i_{s \beta}\right) \\
& +\phi_{r \alpha}\left(\delta \phi_{r \alpha}-a_{2} i_{s \alpha}\right)
\end{aligned}
$$

The derivatives $\dot{\Phi}_{\text {ref }}$ and $\ddot{\Phi}_{\text {ref }}$ are obtained using (11) i.e.:

$\Phi_{\text {ref }}=F\left(I_{s}\right)=h_{0}+h_{1} I_{s}+h_{2} I_{s}^{2}+\cdots+h_{n} I_{s}^{n}$

Specifically, one has:

$\dot{\Phi}_{\text {ref }}=\frac{d F\left(I_{s}\right)}{d t}=\frac{d F\left(I_{s}\right)}{d I_{s}} \frac{d I_{s}}{d t}=\frac{d F\left(I_{s}\right)}{d I_{s}} \frac{i_{s \alpha} \dot{i}_{s \alpha}+i_{s \beta} \dot{i}_{s \beta}}{I_{s}}$

and

$$
\begin{aligned}
\ddot{\Phi}_{r e f}= & \frac{d^{2} F\left(I_{s}\right)}{d I_{s}^{2}}\left(\frac{i_{s \alpha} \dot{i}_{s \alpha}+i_{s \beta} \dot{i}_{s \beta}}{I_{s}}\right)^{2}+\frac{d F\left(I_{s}\right)}{d I_{s}} \frac{\left(\dot{i}_{s \alpha}\right)^{2}+i_{s \alpha} \ddot{i}_{s \alpha}+\left(\dot{i}_{s \beta}\right)^{2}+i_{s \beta} \ddot{i}_{s \beta}}{I_{s}} \\
& -\frac{d F\left(I_{s}\right)}{d I_{s}} \frac{\left(i_{s \alpha} \dot{i}_{s \alpha}+i_{s \beta} \dot{i}_{s \beta}\right)^{2}}{I_{s}^{3}}
\end{aligned}
$$

Note that the derivatives $d F / d I_{S}$ and $d^{2} F / d I_{s}^{2}$ are easily obtained thanks to the polynomial nature of (31). To analyze the error system, composed of equations (21a-b), (25) and (30a), the following augmented Lyapunov function candidate is considered:

$V_{2}=V_{1}+\frac{1}{2}\left(e_{2}^{2}+z_{2}^{2}\right)$

Its time-derivative along the trajectory of the state vector $\left(e_{1}, z_{1}\right.$, $\left.e_{2}, z_{2}\right)$ is

$\dot{V}_{2}=e_{1} \dot{e}_{1}+e_{2} \dot{e}_{2}+z_{1} \dot{z}_{1}+z_{2} \dot{z}_{2}$

Using (22), (25) and (30a), Eq. (35) becomes

$$
\begin{aligned}
\dot{V}_{2}= & -c_{1} e_{1}^{2}-d_{1} z_{1}^{2}+e_{2}\left(e_{1}+\mu_{2}+\frac{p}{J} a_{3}\left(\phi_{r \beta} u_{s \alpha}-\phi_{r \alpha} u_{s \beta}\right)\right) \\
& +z_{2}\left(z_{1}+v_{2}-2 a_{1} a_{3}\left(\phi_{r \alpha} u_{s \alpha}+\phi_{r \beta} u_{s \beta}\right)\right)
\end{aligned}
$$

Adding $c_{2} e_{2}^{2}-c_{2} e_{2}^{2}+d_{2} z_{2}^{2}-d_{2} z_{2}^{2}$ to the right side of (36a) and rearranging terms, yields:

$$
\begin{aligned}
\dot{V}_{2}= & -c_{1} e_{1}^{2}-c_{2} e_{2}^{2}-d_{1} z_{1}^{2}-d_{2} z_{2}^{2} \\
& +e_{2}\left(e_{1}+c_{2} e_{2}+\mu_{2}+\frac{p}{J} a_{3}\left(\phi_{r \beta} u_{s \alpha}-\phi_{r \alpha} u_{s \beta}\right)\right) \\
& +z_{2}\left(z_{1}+d_{2} z_{2}+v_{2}-2 a_{1} a_{3}\left(\phi_{r \alpha} u_{s \alpha}+\phi_{r \beta} u_{s \beta}\right)\right)
\end{aligned}
$$

where $c_{2}$ and $d_{2}$ are new arbitrary positive real design parameters. Eq. (36b) suggests that the control signals $u_{s \alpha}, u_{s \beta}$ must set to zero the two quantities between curly brackets (on the right side of (36b)). Letting these quantities equal to zero and solving the resulting second-order linear equation system with respect to $\left(u_{s \alpha}, u_{s \beta}\right)$, gives the following control law:

$\left[\begin{array}{l}u_{s \alpha} \\ u_{s \beta}\end{array}\right]=\left[\begin{array}{cc}\lambda_{0} & \lambda_{1} \\ \lambda_{2} & \lambda_{3}\end{array}\right]^{-1}\left[\begin{array}{l}-e_{1}-c_{2} e_{2}-\mu_{2} \\ -z_{1}-d_{2} z_{2}-v_{2}\end{array}\right]$

with

$\lambda_{0}=\frac{p}{J} a_{3} \phi_{r \beta}, \quad \lambda_{1}=-\frac{p}{J} a_{3} \phi_{r \alpha} ; \quad \lambda_{2}=-2 a_{1} a_{3} \phi_{r \alpha} ;$
$\lambda_{3}=-2 a_{1} a_{3} \phi_{r \beta}$

Notice that the matrix

$\left[\begin{array}{ll}\lambda_{0} & \lambda_{1} \\ \lambda_{2} & \lambda_{3}\end{array}\right]$

is nonsingular. Indeed, it is easily checked that its determinant is $D=\lambda_{0} \lambda_{3}-\lambda_{1} \lambda_{2}=-2(p / J) a_{1} a_{3} \Phi_{r}^{2}$ which never vanishes in practice because of the machine remnant flux. Substituting the control law (37) to $\left(u_{s \alpha}, u_{s \beta}\right)$ on the right side of (36b) yields:

$\dot{V}_{2}=-c_{1} e_{1}^{2}-c_{2} e_{2}^{2}-d_{1} z_{1}^{2}-d_{2} z_{2}^{2}$

As this is a negative definite function of the state vector $\left(e_{1}, z_{1}, e_{2}, z_{2}\right)$, the closed-loop system is globally asymptotically stable (Khalil, 2003). The result thus established is more precisely formulated in the following theorem:

Theorem 1. (Main result) Consider the closed-loop system composed of the induction machine, described by the model (1)-(6), and of the nonlinear controller defined by the control law (37). Then, the following properties are ensured:

(1) The closed-loop error system undergoes, in the $\left(e_{1}, z_{1}, e_{2}, z_{2}\right)$ coordinates, the following equations:

$$
\begin{aligned}
& \dot{e}_{1}=-c_{1} e_{1}+e_{2} \\
& \dot{z}_{1}=-d_{1} z_{1}+z_{2} \\
& \dot{e}_{2}=-e_{1}-c_{2} e_{2}
\end{aligned}
$$

$\dot{z}_{2}=-z_{1}-d_{2} z_{2}$ 
(2) The above linear system is globally asymptotically stable with respect to the Lyapunov function $V_{2}=\left(e_{1}^{2}+z_{1}^{2}+e_{2}^{2}+z_{2}^{2}\right) / 2$. Consequently, all errors vanish exponentially fast, whatever the initial conditions.

Proof. Eqs. (40a-b) are immediately obtained from (21a-b). Eq. (40c) is obtained substituting the control law (37) to $\left(u_{s \alpha}, u_{s \beta}\right)$ on the right side of (25). Eq. (40d) is obtained substituting the control law (37) to $\left(u_{s \alpha}, u_{s \beta}\right)$ on the right side of (30a). This proves Part 1 . On the other hand, it is readily seen from (17), (34) and (39) that $V_{2}=\left(e_{1}^{2}+z_{1}^{2}+e_{2}^{2}+z_{2}^{2}\right) / 2$ is a Lyapunov function of the error system (40a-d). As $\dot{V}_{2}$ is a negative definite function of the state vector $\left(e_{1}, z_{1}, e_{2}, z_{2}\right)$, the error system is globally asymptotically stable. But the asymptotic stability implies exponential stability due to the system linearity (Khalil, 2003). Theorem 1 is established.

Remark 1. It is known that the exponential nature of stability guarantees stability robustness with respect to modeling and measurements errors (Khalil, 2003).

\section{Simulation results}

This section illustrates the supremacy of the new control strategy (NLM-OF), involving state-dependent optimal flux reference, over control strategies with a constant flux reference, e.g. LM-CF or NLM-CF (see Table 2). The comparison is performed, using a $7.5 \mathrm{~kW}$ induction machine whose characteristics are summarized in Table 3. Then, it is shown that perfect tracking of a varying flux reference is always achieved with the NLM-OF controller (because it is based on a model that accounts for magnetic saturation) but generally not with the LM-OF design (which is based on the standard model that neglects the magnetic saturation). Finally, it will be checked that the NLM-OF strategy preserves its main features in presence of small rotor resistance variation.

\subsection{Supremacy of NLM-OF strategy over LM-CF strategy (Table 2)}

The simulation protocol is conceived so that the machine operates in different conditions which are determined by the load variation law (Fig. 7) and speed reference (Fig. 8). Recall that the NLM-OF controller includes the optimal flux generator described by the characteristic $\Phi_{\text {ref }}=F\left(I_{s}\right)$ (plotted in Fig. 6) and the control law (37). The design parameters are given the following values which proved to be convenient: $c_{1}=5, c_{2}=$ $4000, d_{1}=18, d_{2}=1500$.

For comparison purpose, a LM-CF controller involving constant flux reference is considered. This is simply obtained by considering in (37):

- the flux reference constant and equal to $1.1 \mathrm{~Wb}$, which is the machine nominal flux,

- the parameter $\delta$ constant and equal to $\delta_{L}=780$,

- and the other design parameters with the following values that proved to be convenient for this controller: $c_{1}=15$, $c_{2}=4000, d_{1}=18, d_{2}=1500$.

The controlled induction machine is represented by model (1)-(6) with the characteristics of Table 3. In that model, $\delta$ is varying with the rotor flux according to the relations (4)-(5). Accordingly, $\delta$ takes the particular value $\delta_{L}=780$ whenever the machine operates around the nominal operation point corresponding (on the magnetic characteristic) to a flux value of $1.1 \mathrm{~Wb}$. Therefore, it is expected that the LM-CF controller will perform well whenever the flux reference is constant and equal to $1.1 \mathrm{~Wb}$.

Fig. 8 shows that both controllers (NLM-OF and LM-CF) perform well as long as speed reference tracking is concerned. Indeed, the speed response obtained with both controllers are very close to each other. To distinguish the two responses it is necessary to make a zoom as done in Fig. 9.

Fig. 10 shows the resulting NLM-OF flux reference $\Phi_{\text {ref }}=F\left(I_{s}\right)$ and the LM-CF constant flux reference. It is clearly seen that the state-dependent flux reference (SDOF) varies significantly, matching the changes of load torque and machine speed. Figs. 11 and 12 show the flux tracking performance for both controllers. Both controllers ensure a good asymptotic tracking of their respective flux references. Figs. 13 and 14 illustrate, respectively, the stator currents and resulting Joule loss power when the machine is controlled with each controller. Joule loss power is computed by the usual expression $3 R_{S} I_{S}^{2} / 2(\mathrm{~W})$. It is clearly observed that, in all operation conditions, the NLM-OF controller involves smaller current and Joule loss power compared

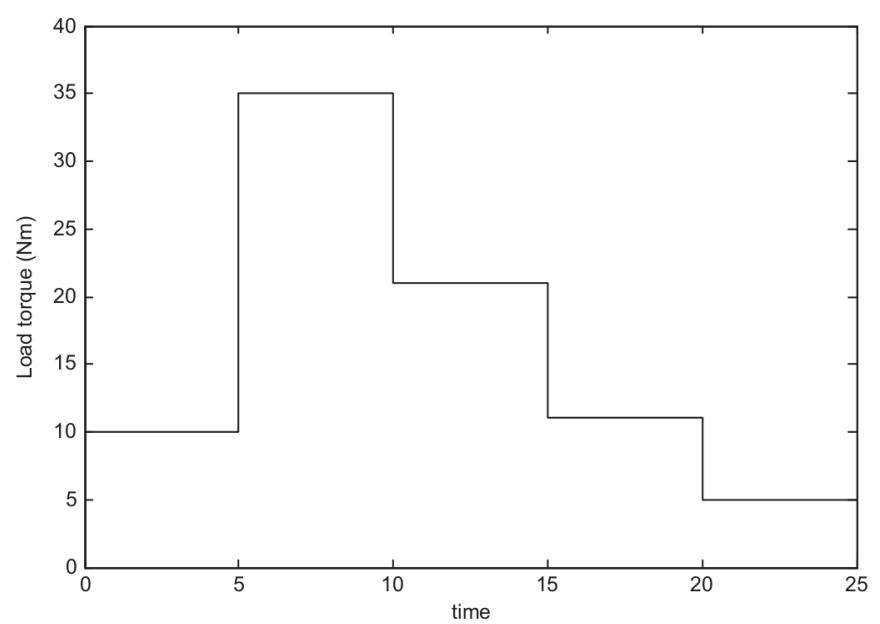

Fig. 7. Applied load torque.

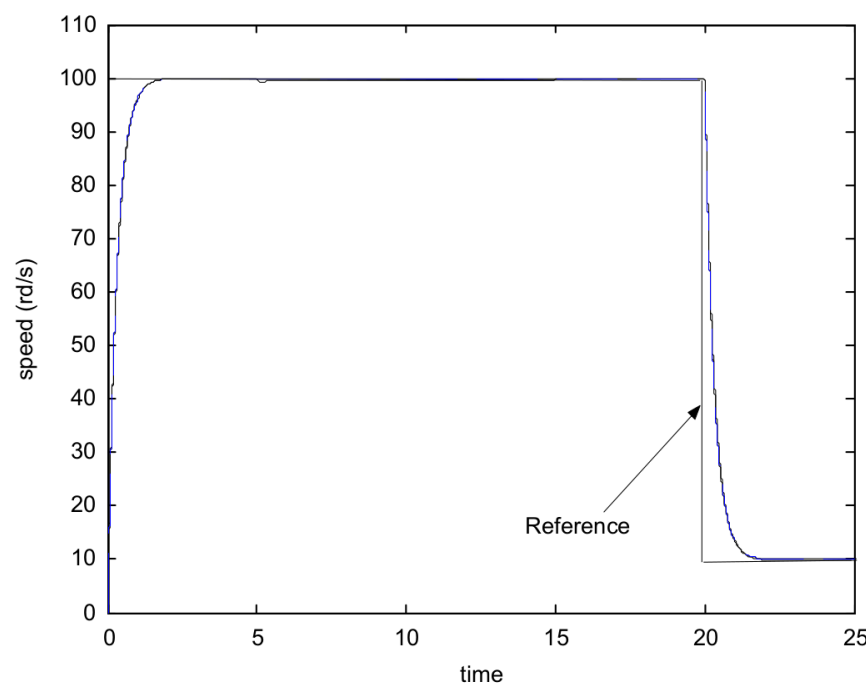

Fig. 8. Speed reference tracking performances obtained with NLM-OF and LM-CF control strategies. Dashed: speed reference. Solid: LM-CF response. Discontinuous: NLM-OF response. The speed responses obtained by LM-CF and NLM-OF strategies are presently too close to each other to be distinguished. 


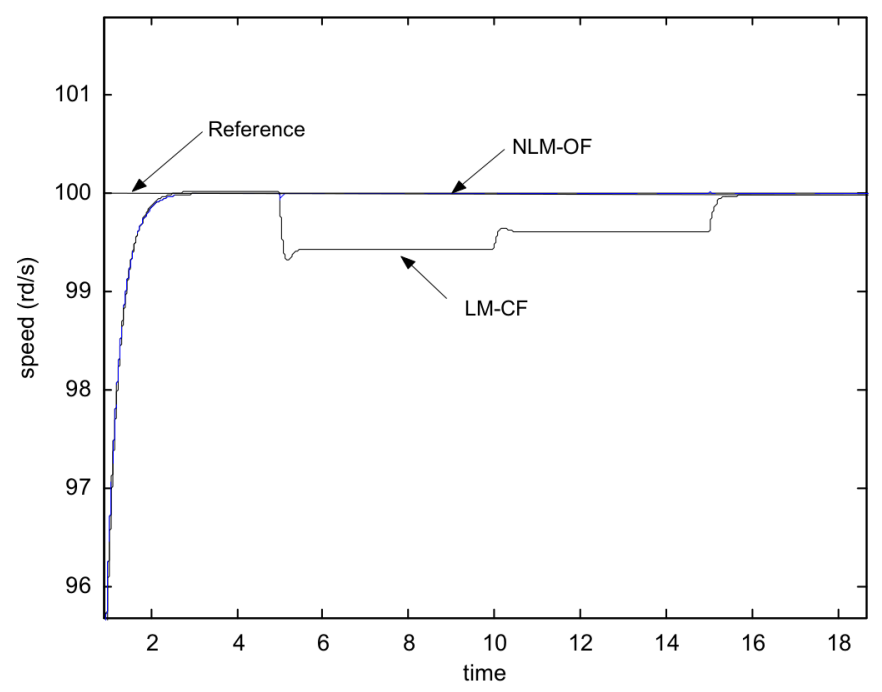

Fig. 9. Zoom on the speed responses of Fig. 8, over the time interval [ $\left[\begin{array}{ll}0 & 18\end{array}\right]$.

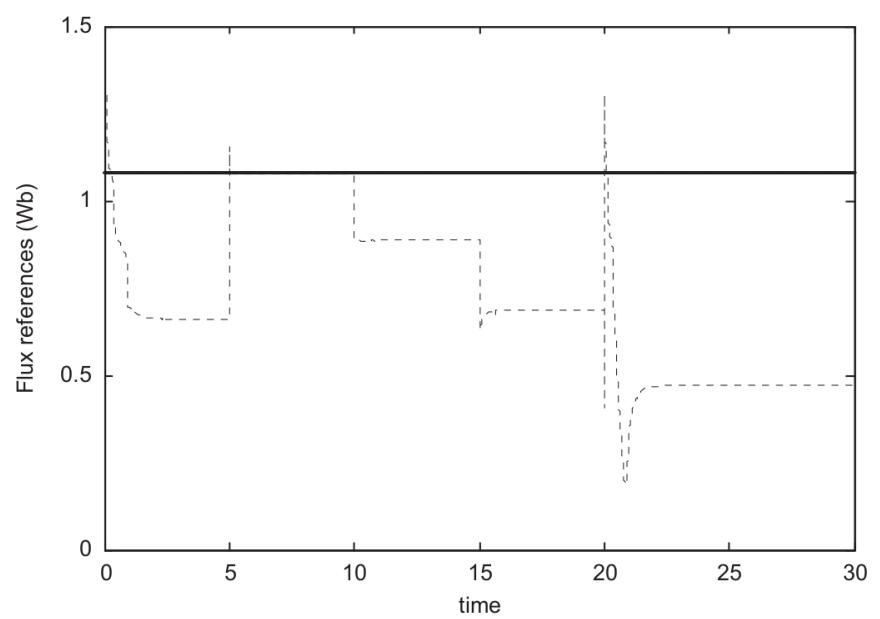

Fig. 10. Rotor flux norm reference (Wb). Solid: LM-CF. Dashed: NLM-OF $\Phi_{\text {ref }}=F\left(I_{s}\right)$.

the LM-CF. Fig. 15 shows the variation of absorbed apparent power $S=3 V_{S} I_{S} / 2$ (VA) when the machine is controlled by each controller. It is again seen that energy consumption is lower when the machine is controlled by the NLM-OF controller. The energy saving achieved by this controller (compared with LM-CF) is evaluated in percent as follows:

$\frac{\int_{0}^{T} S_{L M-C F}(t) d t-\int_{0}^{T} S_{N L M-O F}(t) d t}{\int_{0}^{T} S_{N L M-O F}(t) d t} \times 100=36.12 \%$

where $T=25 \mathrm{~s}$ (duration of the experiment), $S_{L M-C F}$ and $S_{N L M-O F}$ denote the apparent electric power absorbed by the machine when this is steered by the controllers LM-CF and NLM-OF, respectively. That is, the benefit of the NLM-OF control strategy is a quite significant energy saving.

Remark 2. (a) It is worth pointing out that the difference between the two control strategies, from the energy saving viewpoint, is more significant in presence of small load torques. This is explained by the fact that the difference between the SDOF reference and the constant flux reference is maximal in presence of small loads.

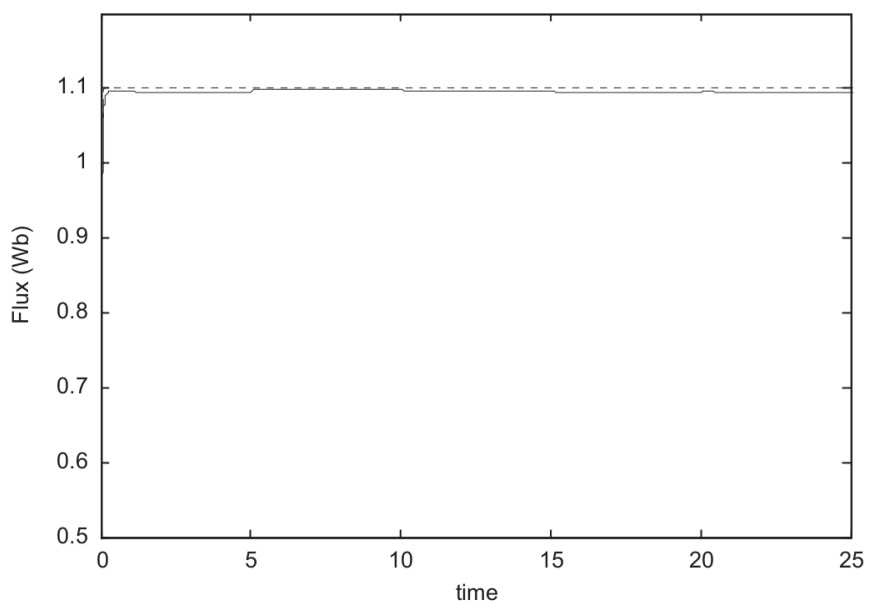

Fig. 11. Flux regulation with the LM-CF control strategy (that involves constant flux reference).

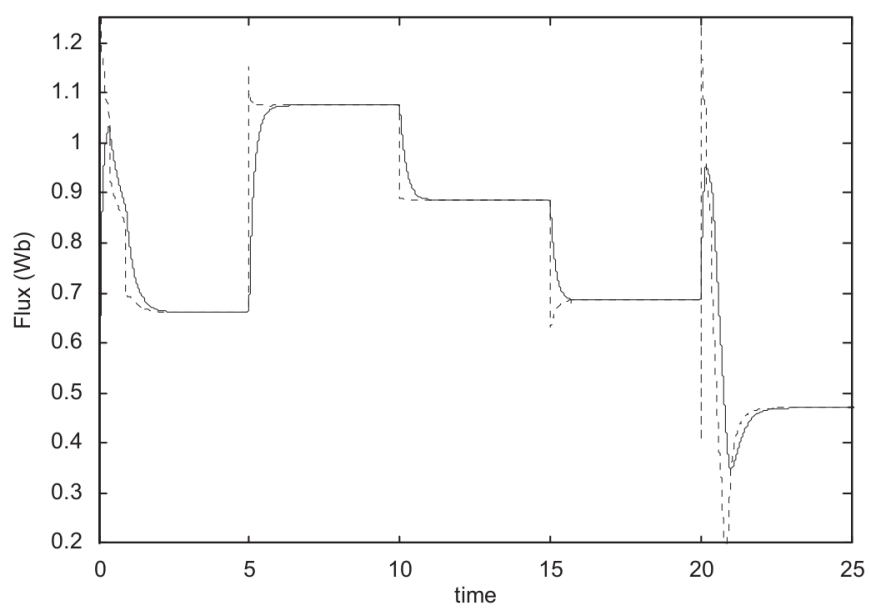

Fig. 12. Flux tracking with NLM-OF controller. Dashed: online generated flux reference $\Phi_{\text {ref }}=F\left(I_{s}\right)$. Solid: measured flux response.

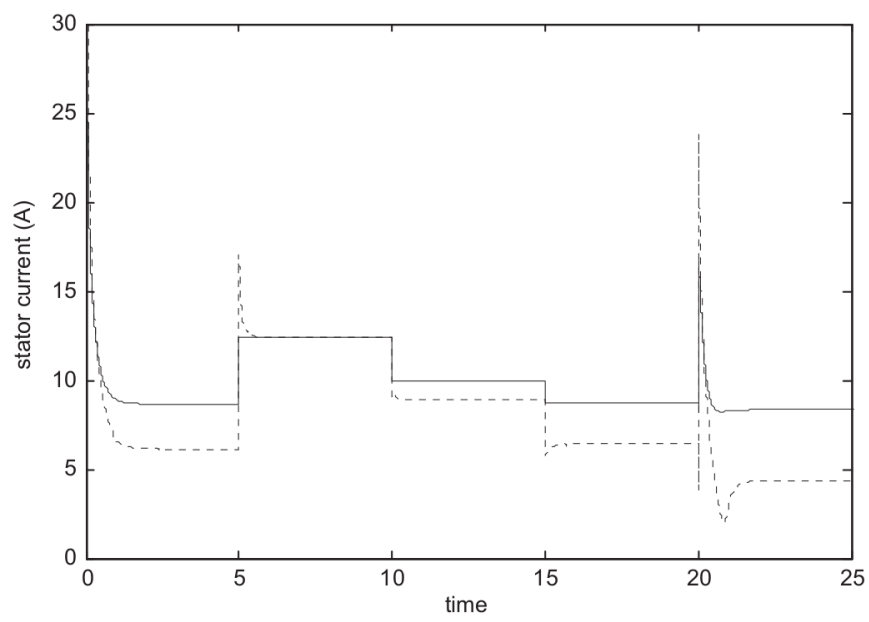

Fig. 13. Absorbed stator current. Solid: LM-CF controller. Dashed: NLM-OF controller.

(b) It can similarly be checked that the NLM-OF strategy is better, from an energetic viewpoint, than the NLM-CF strategy. Actually, there is no difference in steady-state behavior between 


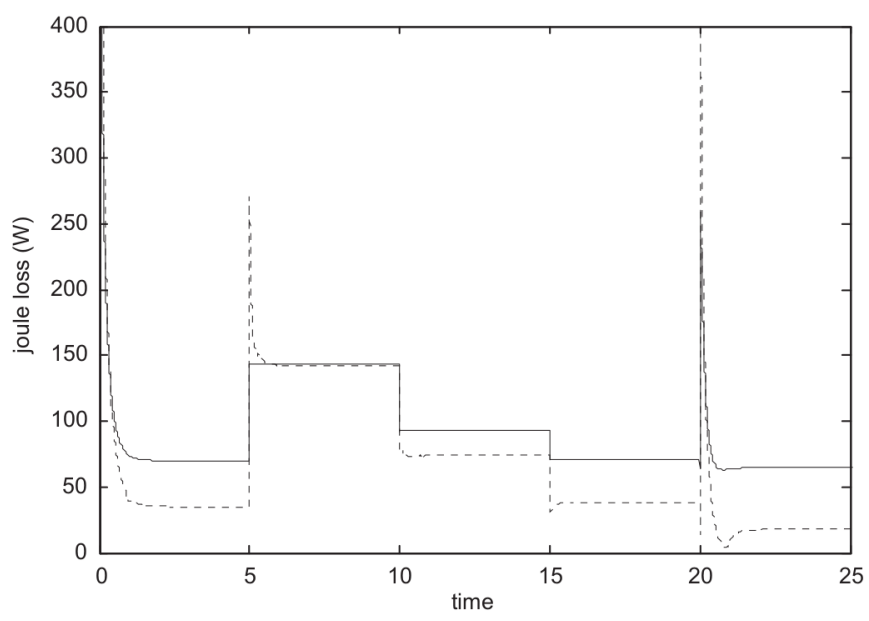

Fig. 14. Joule losses power (W). Solid: LM-CF controller. Dashed: NLM-OF controller.

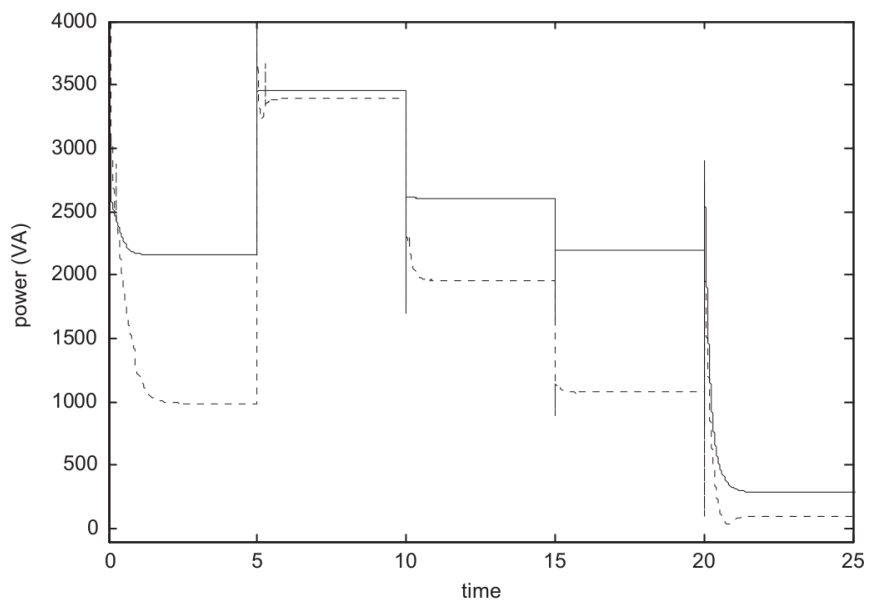

Fig. 15. Absorbed electrical power (VA). Solid: LM-CF controller. Dashed: NLM-OF controller.

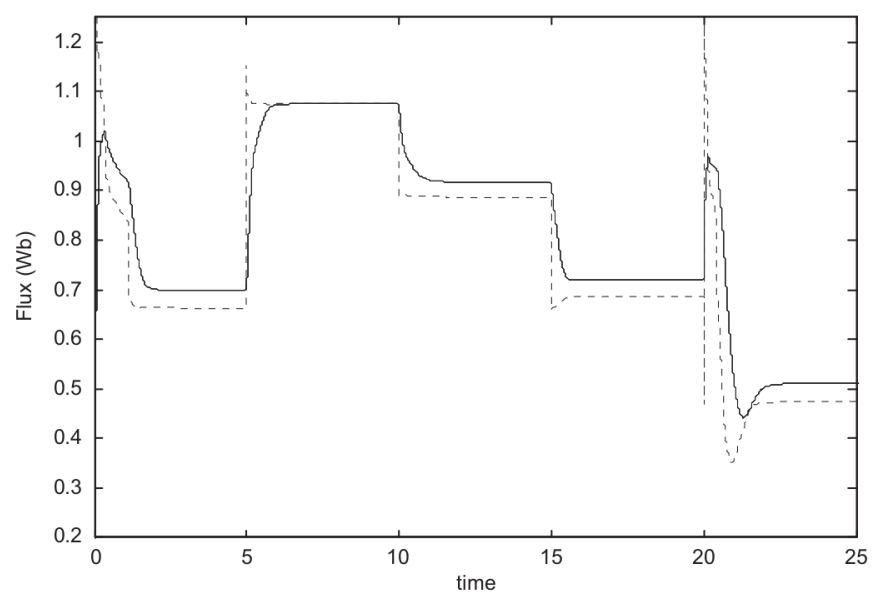

Fig. 16. Flux tracking performance of the LM-OF controller. Dashed: flux reference $\Phi_{r e f}=F\left(I_{s}\right)$. Solid: measured flux with LM-OF.

the NLM-CF and LM-CF control strategies as long as the (constant) flux reference is at its nominal value $1.1 \mathrm{~Wb}$. As both controllers ensure perfect flux reference tracking, it follows that the real rotor flux converges to its nominal value. Then, the quantity $\delta$ in the NLM-model converges to the specific value $\delta_{L}=780$. Hence, the NLM-model reduces to the LM-model.

\subsection{Supremacy of NLM-OF strategy over LM-OF strategy}

The simulation protocol is similar to the one given in Section 6.1 (Figs. 7 and 8). Recall that the NLM-OF controller is defined by the control law (37) together with the optimal flux generator $\Phi_{\text {ref }}=F\left(I_{s}\right)$ (plotted in Fig. 6). The controller design parameters are given the following values which proved to be convenient: $c_{1}=5, c_{2}=4000, d_{1}=18, d_{2}=1500$. The NLM-OF controller is now compared with a controller of the LM-OF type (Table 1). The later is simply obtained making the following modifications in (37):

- the flux reference is given by the optimal flux generator $\Phi_{\text {ref }}=F\left(I_{s}\right)$ (Fig. 6),

- the parameter $\delta$ in (37) is kept constant and equal to $\delta_{L}=780$, and

- the remaining design parameters are given the following values that proved to be convenient for this controller: $c_{1}=5, c_{2}=4000, d_{1}=18, d_{2}=1500$.

Figs. 16 and 17 show the flux tracking quality achieved with the NLM-OF and LM-OF control strategies, respectively. It is observed that the former generally ensures a tighter flux tracking than the latter. Fig. 18 shows that both controllers ensure a perfect asymptotic tracking of the speed reference signal. Fig. 19 shows that stator current is smaller with the NLM-OF controller. This is particularly true in presence of small load torques because the machine operational conditions are then very different from the nominal conditions. The supremacy of the NLM-OF controller, from the energetic viewpoint, is further illustrated by Fig. 20 where the absorbed power is plotted for both controllers. The energy saving achieved with the NLM-OF controller during the present simulation is evaluated as follows:

$\frac{\int_{0}^{T} S_{L M-O F}(t) d t-\int_{0}^{T} S_{N L M-O F}(t) d t}{\int_{0}^{T} S_{N L M-O F}(t) d t} \times 100=18.41 \%$

where the different notations are similar to (41). Again, the energy saving obtained with the NLM-OF controller strategy, compared to the LM-OF, is quite significant.

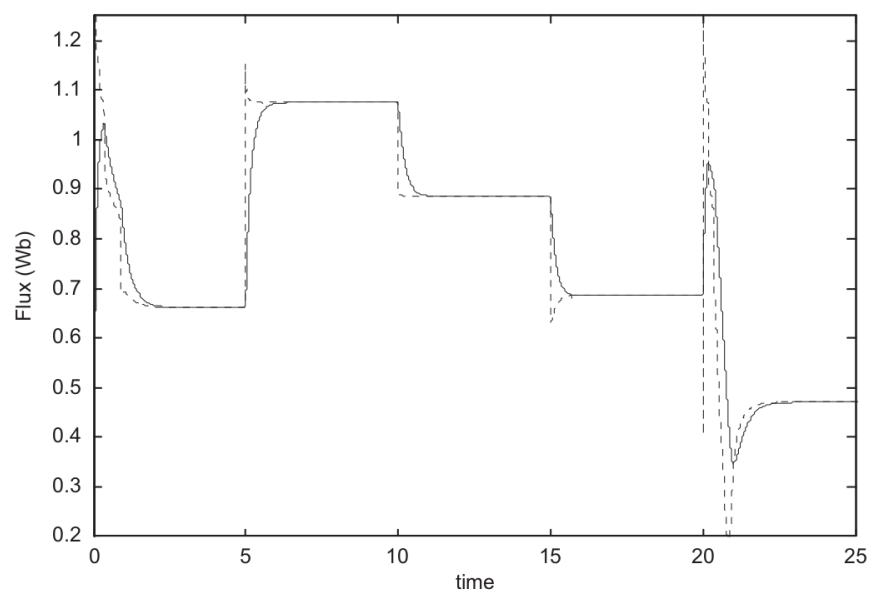

Fig. 17. Flux tracking performance of the NLM-OF controller. Dashed: flux reference $\Phi_{\text {ref }}=F\left(I_{s}\right)$. Solid: response with NLM-OF. 


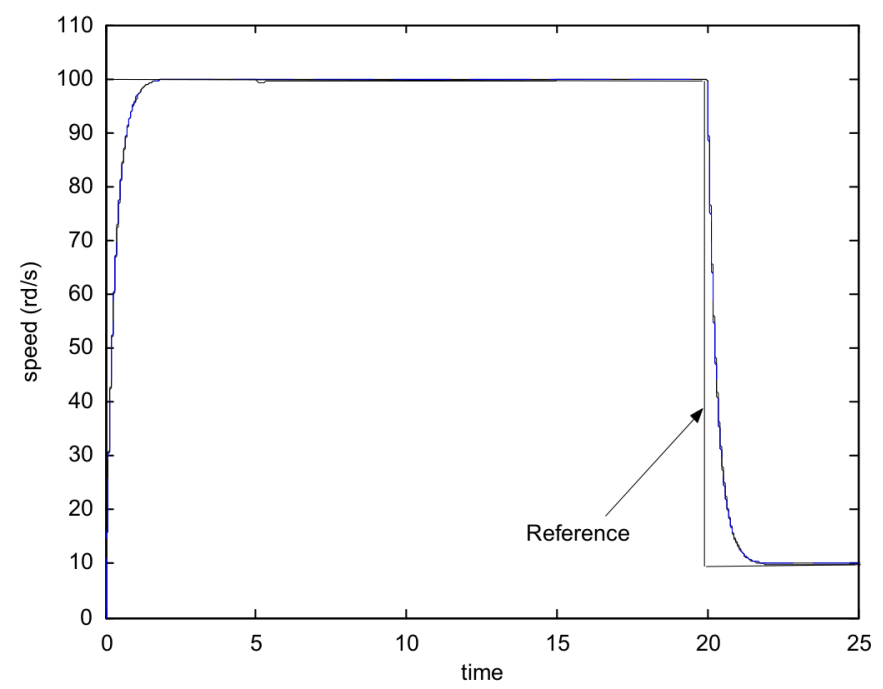

Fig. 18. Speed tracking performance of NLM-OF and LM-OF controllers. Dashed: speed reference. Solid: LM-OF speed response. Discontinuous: NLM-OF speed response. The responses of both controllers are too close to each other to be distinguished.

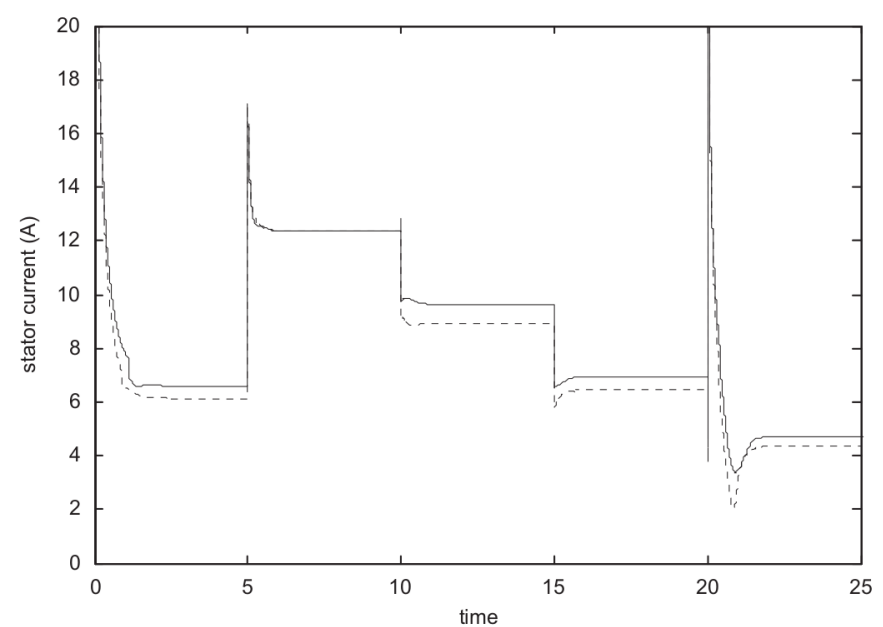

Fig. 19. Absorbed stator current. Solid: LM-OF controller. Dashed: NLM-OF controller.

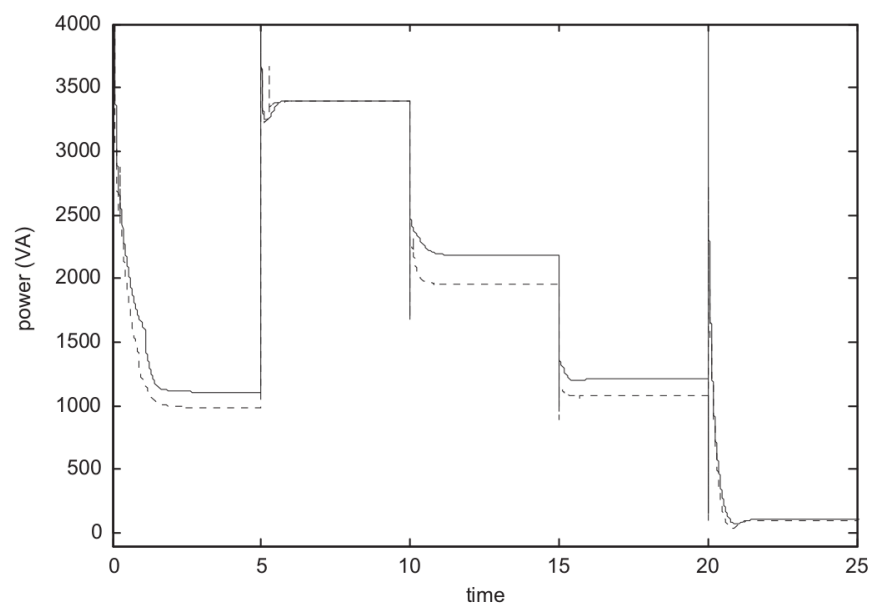

Fig. 20. Absorbed electrical power (VA). Solid: LM-OF controller. Dashed: NLM-OF controller.

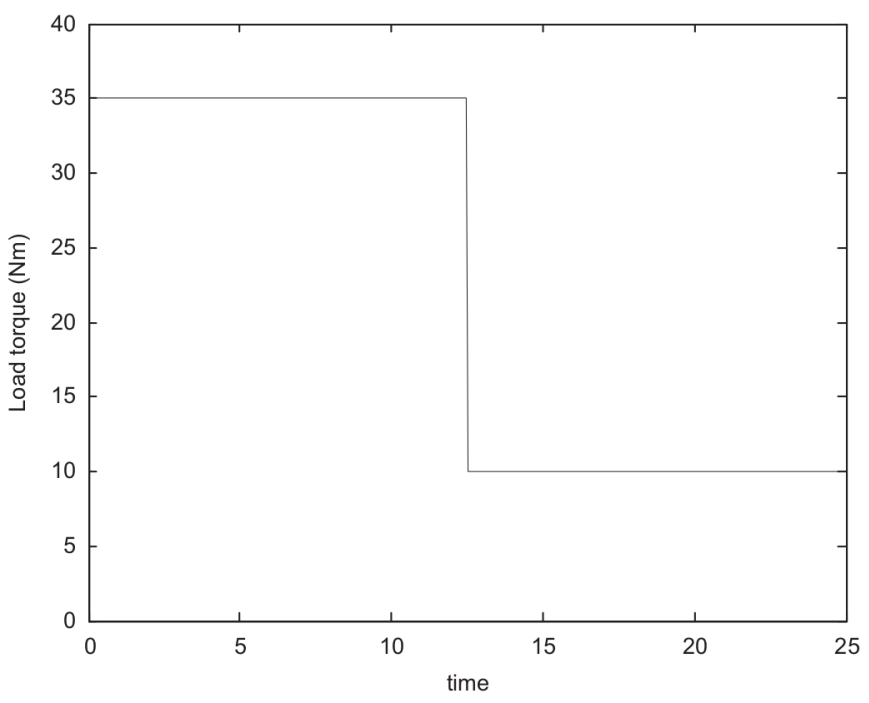

Fig. 21. Load torque variation when rotor resistance uncertainty is considered.

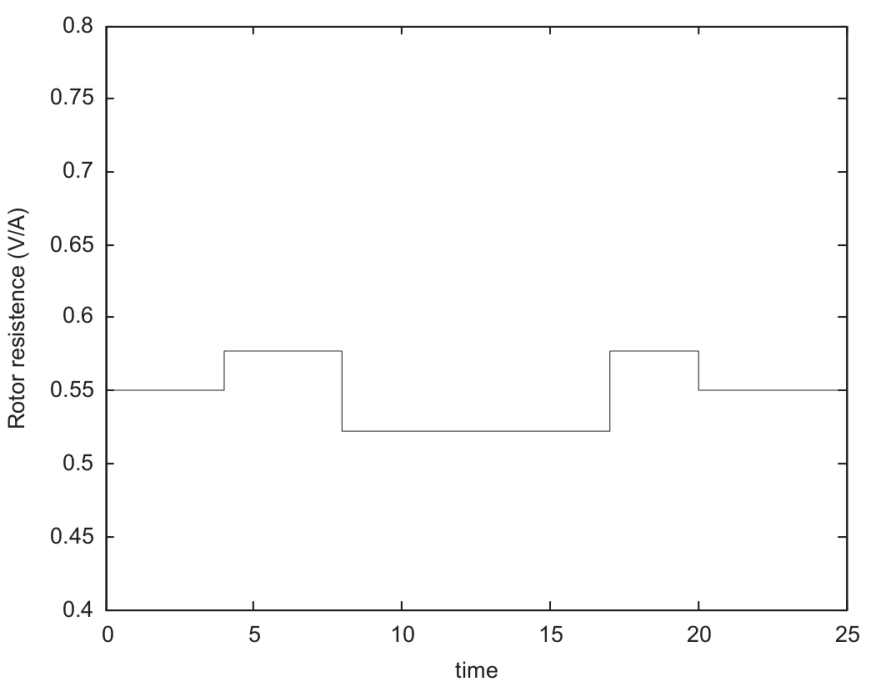

Fig. 22. Variation of rotor resistance $R_{r}$.

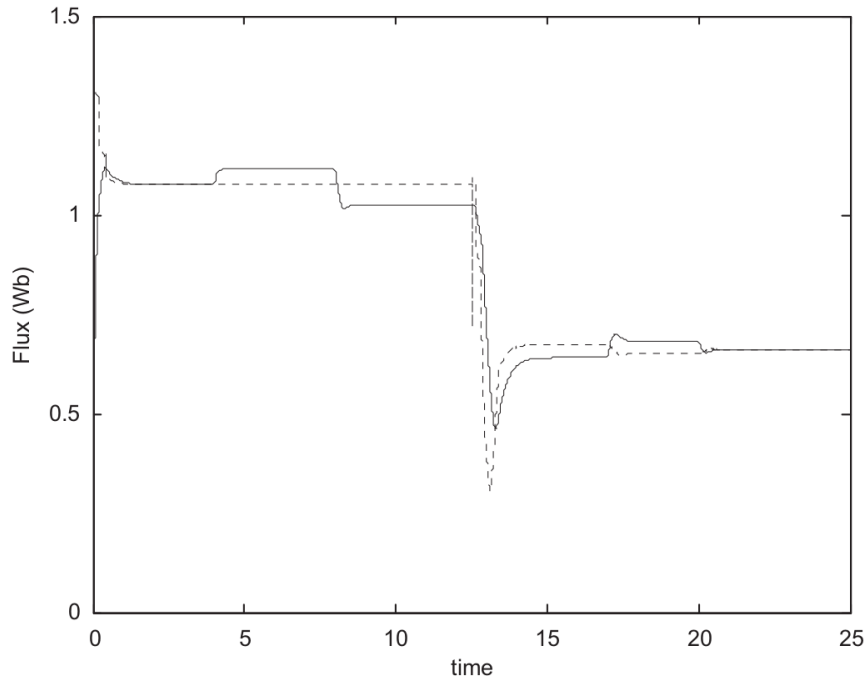

Fig. 23. Flux tracking performance of the NLM-OF controller operating in presence of rotor resistance uncertainty. Dashed: flux reference. Solid: measured flux. 


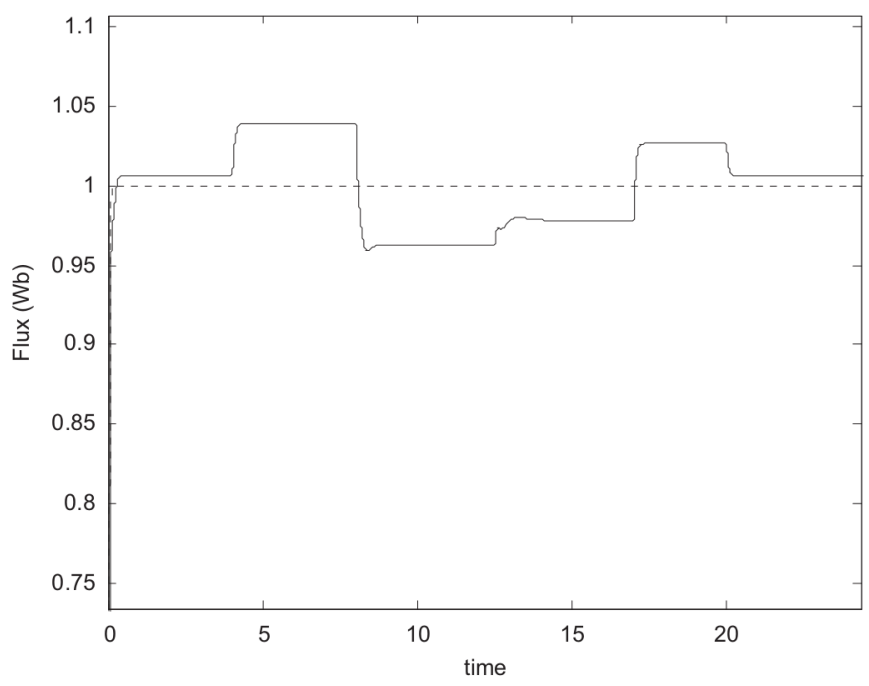

Fig. 24. Flux tracking performance of the LM-CF controller operating in presence of rotor resistance uncertainty. Dashed: flux reference. Solid: measured flux.

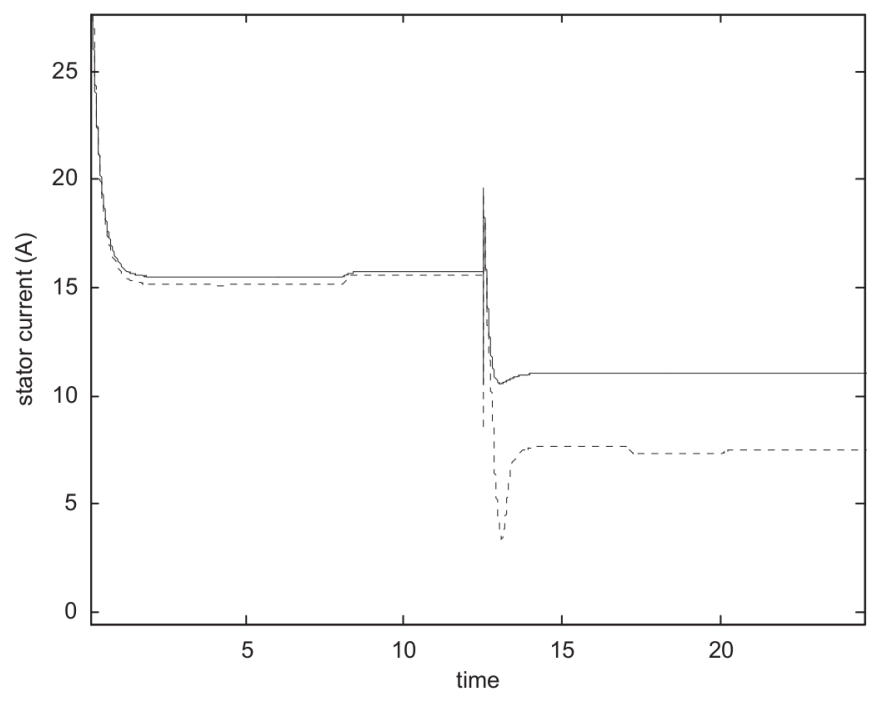

Fig. 25. Absorbed stator current with $\mathrm{LM}-\mathrm{CF}$ and $\mathrm{LMN}-\mathrm{OF}$ controllers operating in presence of rotor resistance uncertainty. Solid: LM-CF controller. Dashed: NLM-OF controller.

\subsection{Robustness of considered control strategies}

In real life operation, rotor resistance is subject to (small) variations due to changes in operating conditions. Then, it is of practical interest to investigate how robust the new control strategy NLM-OF is with respect to rotor resistance uncertainty and to compare its sensitivity to that of the classical LM-CF strategy. To this end, consider again the NLM-OF and LM-CF controllers used in Subsection 6.1 of the present section. The simulation protocol is the following:

- the load torque changes significantly during the simulation as shown in Fig. 21 and

- the rotor resistance $R_{r}$ varies around its nominal value $0.55 \Omega$, it deviates up to $\pm 5 \%$ (Fig. 22 ).

Obviously, the rotor resistance variations are not accounted for in the controllers i.e. $R_{r}$ is kept constant therein, with its nominal value.

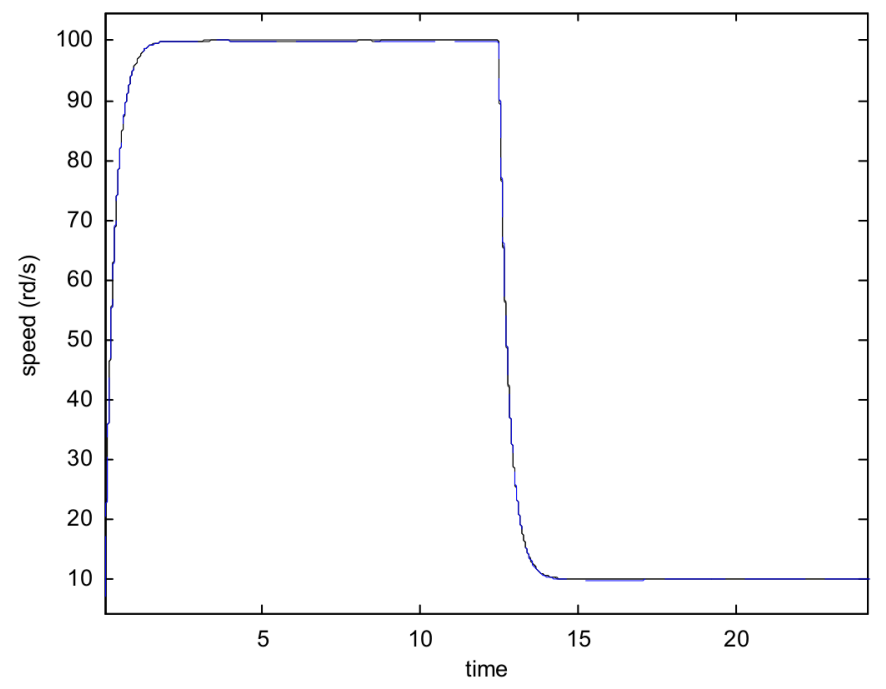

Fig. 26. Speed tracking performance of NLM-OF and LM-OF controllers in presence of rotor resistance uncertainty. Dashed: speed reference. Solid: LM-OF speed response. Discontinuous: NLM-OF speed response. The responses of both controllers are too close to each other to be distinguished.

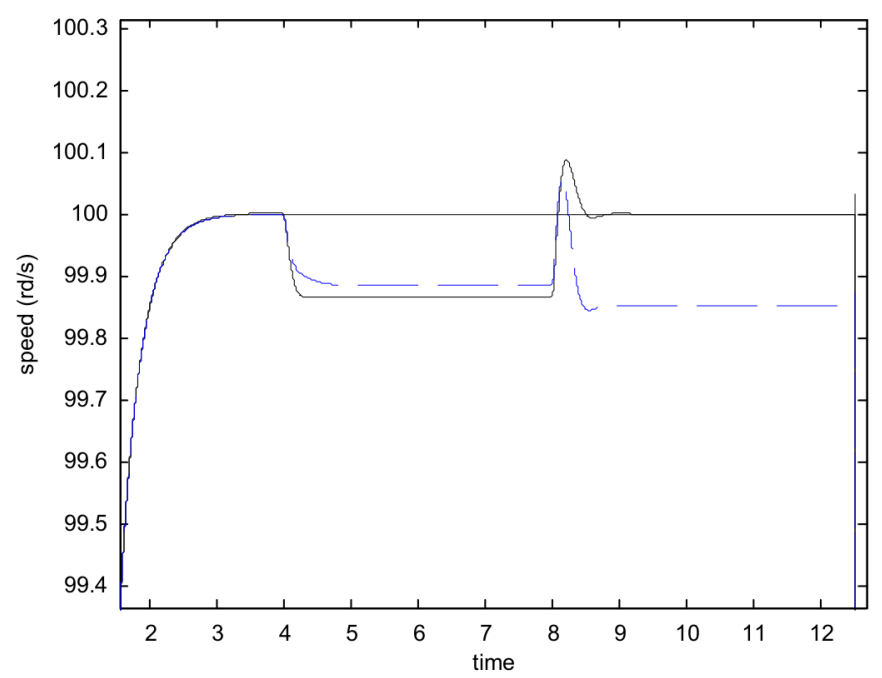

Fig. 27. Zoom on the speed responses of Fig. 25, over the time interval [ $\left.\begin{array}{ll}1 & \mathrm{~s} \\ 13 & \mathrm{~s}\end{array}\right]$.

Fig. 23 shows the flux tracking quality of the NLM-OF controller. A small tracking error, less than $5 \%$, is observed whenever the rotor resistance deviates from its nominal value (used in the controller). A roughly similar sensitivity level is observed in Fig. 24 for the LM-CF controller. Interestingly, the sensitivity of both controllers (to resistance uncertainties) is much smaller when it comes to stator current absorption (Fig. 25). This means, in particular, that current optimization is still ensured by the NLM-OF controller and, from this viewpoint, the NLM-OF is quite better than the LM-CF. Finally, it follows from Figs. 26 and 27 that the good speed tracking capability of both controllers is insensitive to resistance uncertainty.

\section{Conclusion}

The problem of induction machine control in presence of magnetic circuit saturation was considered in this paper. A new speed-flux controller described by (37) and based on the model (1)-(6) is designed using the backstepping technique. The proposed controller involves a state-dependent flux reference 
generator. The flux state dependence is resorted to optimize the absorbed stator current. It is formally shown (Theorem 1) that the proposed controller guarantees the global convergence of the speed and flux errors $e_{1}=\Omega_{r e f}-\Omega$ and $z_{1}=\Phi_{r e f}^{2}-\Phi_{r}^{2}$ to zero (with $\Phi_{r}^{2}=\phi_{r \alpha}^{2}+\phi_{r \beta}^{2}$ ). That is, the tracking objective is perfectly achieved both for the machine speed and rotor flux. Furthermore, it is shown by simulation that, in all operation conditions, the absorbed stator current is actually smaller with the proposed NLM-OF controller, compared to more standard LM-CF, NLM-CF or LM-OF controllers. Such a supremacy of the NLM-OF controller is preserved in presence of small resistance uncertainties. An adaptive version of the proposed NLM-OF control strategy has yet to be designed to face large resistance uncertainties.

\section{References}

Espinosa, G., Ortega, R., \& Nicklasson, P. J. (1997). Torque and flux tracking of induction motors. International Journal of Robust and Nonlinear Control, 7(1), $1-9$.

Giri, F., Elfadili, A., Ouadi, H., Dugard, L., \& Buche, G. (2008). Discrete-time observer for induction machine in presence of magnetic saturation. In IFAC world congress, Seoul, Korea.

Heinemann, G., \& Leonhard, W. (1990). Self-tuning field-oriented control of an induction motor drive. In International power electronics conference, Tokyo, Japan.
Khalil, H. (2003). Nonlinear systems. Englewood Cliffs, NJ: Prentice-Hall.

Kim, K., Ortega, R., Charara, A., \& Vilain, J. P. (1997). Theoretical and experimental comparison of two nonlinear controller for induction motors. IEEE Transactions on Control Systems Technology, 5(3), 338-348.

Krstic, M., Kanellakopoulos, I., \& Kokotovic, P. (1995). Nonlinear and adaptive control design. New York: Wiley.

Kwon, C., \& Sudhoff, S. D. (2005). An adaptive maximum torque per amp control strategy. In IEEE international conference on electric machines and drives (pp. 783-788).

Leonard, W. (2001). Control of electrical drives. Berlin: Springer.

Lubineau, D., Dion, J. M., Dugard, L., \& Roye, D. (2000). Design of an advanced nonlinear controller for induction motor and experimental validation on an industrial benchmark. EPJ Applied Physics, 9, 165-175.

Novotnak, R. T., Chiasson, J., \& Bodson, M. (1999). High performance motion control of an induction motor with magnetic saturation. IEEE Transactions on Control Systems Technology, 7(3), 315-327.

Ortega, R., \& Espinosa, G. (1993). Torque regulation of induction motors. Automatica, 29(3), 621-633.

Ortega, R., Nicklasson, P. J., \& Espinosa-Perez, G. (1996). On speed control of induction motors. Automatica, 32(3), 455-460.

Ouadi, H., Giri, F., \& Dugard, L. (2004). Modelling saturated induction motors. In IEEE conference on control applications (CCA'04) (Vol. 1, pp. 75-80). Taipei, Taiwan.

Von Raumer, T., Dion, J. M., Dugard, L., \& Thomas, J. L. (1994). Applied nonlinear control of an induction motor using digital signal processing. IEEE Transactions on Control Systems Technology, 2(4), 327-335.

Wasynczuk, O., Sudhoff, S. D., Corzine, K. A., Tichenor, J. L., Krause, P. C., Hansen, I. G. et al. (1998). A maximum torque per ampere control strategy for induction motor drives. IEEE Transactions on Energy Conversion 13(2), 163-169. 